\title{
Single Amino Acid Changes in the 6K1-Cl Region Can Promote the Alternative Adaptation of Prunus- and Nicotiana-Propagated Plum pox virus C Isolates to Either Host
}

\author{
María Calvo, ${ }^{1}$ Tadeusz Malinowski, ${ }^{2}$ and Juan Antonio García ${ }^{1}$ \\ ${ }^{1}$ Departamento de Genética Molecular de Plantas, Centro Nacional de Biotecnología (CNB-CSIC), Campus Universidad \\ Autónoma de Madrid, 28049 Madrid, Spain; 'Zakład Biologii Ogólnej i Molekularnej, Instytut Ogrodnictwa, Konstytucji 3 \\ Maja 1/3, 96-100 Skierniewice, Poland
}

Submitted 23 August 2013. Accepted 11 October 2013.

\begin{abstract}
Plum pox virus (PPV) $\mathrm{C}$ is one of the less common PPV strains and specifically infects cherry trees in nature. Making use of two PPV-C isolates that display different pathogenicity features, i.e., SwCMp, which had been adapted to Nicotiana species, and BY101, which had been isolated from cherry rootstock L2 (Prunus lannesiana) and propagated only in cherry species, we have generated two infective full-length cDNA clones in order to determine which viral factors are involved in the adaptation to each host. According to our results, the C-P3(PIPO)/6K1/N-CI (cylindrical inclusion) region contains overlapping but not coincident viral determinants involved in symptoms development, local viral amplification, and systemic movement capacity. Amino acid changes in this region promoting the adaptation to $N$. benthamiana or $P$. avium have trade-off effects in the alternative host. In both cases, adaptation can be achieved through single amino acid changes in the NIapro protease recognition motif between $6 \mathrm{~K} 1$ and $\mathrm{CI}$ or in nearby sequences. Thus, we hypothesize that the potyvirus polyprotein processing could depend on specific host factors and the adaptation of PPV-C isolates to particular hosts relies on a fine regulation of the proteolytic cleavage of the 6K1-CI junction.
\end{abstract}

Plum pox virus (PPV) is a member of the genus Potyvirus belonging to the Potyviridae family. The genome of PPV consists of a single-stranded RNA genome of positive polarity of around $9.8 \mathrm{~kb}$ in length, which is translated into a large polyprotein and a smaller product that is originated from a translation frameshift (Chung et al. 2008; Salvador et al. 2006). The polyprotein is cleaved by three self-encoded proteases, i.e., P1, HCpro, and NIapro (López-Moya et al. 2000).

PPV is the causal agent of the devastating sharka disease in Prunus species (García et al. 2013; Sochor et al. 2012; Šubr and Glasa 2013), which was first detected in plum trees from Bulgaria in 1915 (Atanasoff 1932). Nowadays, the disease has

Corresponding author: J. A. García; E-mail: jagarcia@cnb.csic.es

* The $e$-Xtra logo stands for "electronic extra" and indicates that three supplementary figures and two supplementary tables, and supplementary text are published online and that Figures 2, 3, 4, and 7 appear in color online.

(C) 2014 The American Phytopathological Society spread to many countries inside and outside Europe (Cambra et al. 2006a) and several PPV strains infecting Prunus species of both agronomical and ornamental importance as well as wild species have been identified and classified thanks to the implementation of serological and nucleic acid-based methods (Cambra et al. 2006b; Olmos et al. 2007; Pasquini et al. 2008; Varga and James 2006).

The most prevalent PPV strains are M (Marcus), D (Dideron), and Rec (Recombinant), which mostly infect plum, peach, and apricot species (Candresse and Cambra 2006). Other minor strains have a more limited or less recognized geographical distribution, such as EA (El Amar) (Wetzel et al. 1991), W (Winona) (James and Varga 2005), and T (Turkey) (Serçe et al. 2009) or a more restricted natural host range, which is the case for strains C (Cherry) (Crescenzi et al. 1997; Nemchinov and Hadidi 1996) and the recently described CR (Cherry-Russia) (Glasa et al. 2013). Interestingly, C and CR are the only PPV strains that have been found in cherry species in nature.

Since, for a long time, no PPV-infected cherry trees had been found in the field, these species were thought to be resistant to PPV. Moreover, under experimental conditions, aphid transmission and chip grafting of the $\mathrm{M}$ and $\mathrm{D}$ strains from infected Prunus persica plants to different cherry rootstocks only caused transient infections and the virus remained localized to the inoculated leaves (Dosba et al. 1987). It was not until the second half of the 1990s that atypical PPV isolates naturally infecting sour and sweet cherry trees in Moldova and Italy were described and named SoC and SwC, respectively. According to molecular and serological data, these highly similar isolates were grouped together giving rise to the $\mathrm{C}$ strain of PPV (Crescenzi et al. 1997; Nemchinov and Hadidi 1996; Nemchinov et al. 1996). Additional PPV-C infections have also been detected in Hungary (Nemchinov et al. 1998) and, more recently, in Croatia (Kajic et al. 2012) and Belarus (Malinowski et al. 2012). Despite the fact that cherry-infecting PPV strains (C and CR) are more prevalent than it was initially thought, there is no solid data on the economical relevance of PPV-C for cherry cultivation.

According to sequence analyses, PPV-C is one of the most genetically divergent PPV strains but is the most closely related to PPV-CR (Chirkov et al. 2013; Glasa et al. 2013). When compared with the M, D, and EA strains, none of which are known to infect cherry species under natural conditions, the most divergent viral regions are the ones corresponding to the $5^{\prime}$ untranslated region and to the coding sequences of $\mathrm{P} 1, \mathrm{P} 3$, and the N-terminal domain of coat protein (CP) (Fanigliulo et 
al. 2003). However, these data have not shed light on the contribution of any of these regions to the particular host specificity of PPV-C.

A usual approach to characterize viral isolates has been the use of experimental herbaceous hosts such as Nicotiana species in which many viruses, including PPV, can be propagated (Goodin et al. 2008; van Oosten 1970). However, it is necessary to take into consideration that the maintenance of PPV isolates in these herbaceous species can induce the appearance of adaptive changes in the viral genome that can have detrimental effects on the ability to infect Prunus species. In this sense, the development of full-length viral cDNA infectious clones has been the major biotechnological approach that has enabled the genetic engineering of viral genomes for the identification of pathogenicity determinants involved in the adaptation of viruses, in particular PPV, to herbaceous and woody hosts (Dallot et al. 2001; Maliogka et al. 2012; Salvador et al. 2008).

Full-length cDNA infectious clones of PPV isolates belonging to the M, D, and Rec strains have been constructed using the viral progeny of several isolates (López-Moya and García 2000; Maiss et al. 1992; Predajňa et al. 2012; Riechmann et al. 1990; Sáenz et al. 2000; Salvador et al. 2008; Tobias et al. 2001). In this article, we report the construction of full-length cDNA clones of two PPV isolates of the $\mathrm{C}$ strain, one that had been propagated exclusively in Prunus species and another that had been adapted to Nicotiana spp. These clones have been used for the identification of viral genetic determinants involved in the adaptation to both hosts in regard to their local amplification and systemic movement capacity, through the development of chimerical constructs by classical cloning and DNA shuffling methods.

\section{RESULTS}

Construction of a full-length cDNA infectious clone from a PPV-C isolate propagated in Nicotiana clevelandii.

A genomic full-length cDNA clone from a PPV isolate of the $\mathrm{C}$ strain, which had been propagated in $N$. clevelandii in several laboratories, was assembled to be used as a genetic tool in order to identify pathogenicity determinants involved in the adaptation of this unusual PPV strain to herbaceous and woody hosts.

The sequence of the cDNA clone was very similar to that of the isolate PPV-SwC (SwC), from which the parental isolate originates, in approximately its first 7,200 nt (GenBank Y09851.2). Surprisingly, the sequence of the $3^{\prime}$ terminal region of the parental isolate and its cDNA clone mostly resembled that of the isolate PPV-SoC (SoC) (GenBank AY184478.1) (Supplementary Fig. S1). Thus, the cloned isolate appears to be a recombinant between $\mathrm{SwC}$ and SoC. However, the origin of the recombination event remains unclear. Hereafter, this recombinant isolate will be designated as $\mathrm{SwCMp}$, with $\mathrm{p}$ standing for parental, and the full-length cDNA clone and its virus progeny will be referred to as pICPPV-SwCM and SwCM, respectively.

The biological properties of the progeny of pICPPV-SwCM resemble those previously described for $\mathrm{SwC}$ or $\mathrm{SoC}$ in herbaceous hosts and $P$. persica, but the cloned isolate has a low infectivity in $P$. avium, its natural host.

The pICPPV-SwCM cDNA clone was highly infectious when inoculated onto $N$. clevelandii plants by particle bombardment. It caused local and systemic necrotic mottling very similar to the symptoms caused in this host by the parental isolate $\mathrm{SwCMp}$ and those reported for the $\mathrm{SwC}$ isolate (Crescenzi et al. 1997). The systemically infected tissue of the biolistically inoculated $N$. clevelandii plants was used as inoculum to test the infectivity of the cloned virus in the herbaceous hosts
Nicotiana benthamiana, Chenopodium foetidum, and Arabidopsis thaliana. The behavior of SwCM in these plants resembled that which had been previously described for SwC or SoC (Crescenzi et al. 1997; Decroocq et al. 2006; Fanigliulo et al. 2003). Thus, SwCM caused systemic necrosis with consequent plant death in N. benthamiana (Fanigliulo et al. 2003) and, in contrast to PPV isolates of other strains, was not able to infect C. foetidum (Crescenzi et al. 1997) and A. thaliana (Decroocq et al. 2006) (Table 1).

The pICPPV-SwCM cDNA clone was used for particle bombardment inoculation of different 5-year-old cherry rootstocks derived from $P$. avium and $P$. mahaleb, in which only a local infection on inoculated leaves and not a systemic infection was detected (data not shown). Further infectivity assays were performed using seedlings of $P$. avium ('Pontavium' and an unknown cultivar) and also P. persica 'GF305'.

Initially, $P$. avium and $P$. persica seedlings were inoculated with SwCM by particle bombardment (Table 2). Both $P$. persica and $P$. avium seedlings developed a local infection on inoculated leaves. However, only one of six $P$. avium seedlings got systemically infected, as determined by immunoblot analysis (Supplementary Fig. S2A and B). No symptoms were observed in the infected plant.

We took advantage of the ability of SwCM to replicate to high levels in $N$. clevelandii to obtain a high-dosage inoculum to be used for mechanical hand-inoculation of $P$. avium seedlings. In this case, viral CP was detected by immunoblot analysis in upper leaves of four of nine seedlings at around 24 days postinoculation (dpi). However, only two seedlings developed systemic symptoms of infection that were observed at approximately 60 dpi. Symptoms in both seedlings appeared as necrotic spots located in one single leaf that did not progress to upper leaves (Table 2). The SwCM progeny of one of the infected seedlings was analyzed by reverse transcription-polymerase chain reaction (RT-PCR) amplification and sequencing of viral cDNA fragments covering the entire genome, but no mutations were found. Systemic infections did not persist after one cycle of vernalization in any of the $P$. avium seedlings.

According to these results, despite being classified as an isolate of the $\mathrm{C}$ strain, $\mathrm{SwCM}$ is not able to infect $P$. avium efficiently.

\section{PPV-C isolates propagated in $P$. avium cause delayed and mild infection or do not infect Nicotiana plants.}

Highly similar PPV-C isolates BY101 and BY181 have been obtained from cherry rootstocks (P. lannesiana and $P$. padus $\times$ $P$. cerasus, respectively) in Belarus, and propagated in $P$. avium $\times$ P. pseudocerasus 'Colt' (Malinowski et al. 2012).

The deduced amino acid sequence of isolates BY101 (GenBank HQ840517.1) and SwCM differed in 29 positions, including those in the PIPO open reading frame (Fig. 1). The comparison was then extended to strain $\mathrm{C}$ isolates not adapted to cherry that had been propagated in Nicotiana species ( $\mathrm{SwC}$ and SoC), isolates adapted to cherry from the $\mathrm{C}$ and $\mathrm{CR}$ strains (GenBank HQ840518.1, KC020124.1, and KC020125.1), and other PPV isolates that do not infect cherry species in nature belonging to D (GenBank EF569214.1) and M (GenBank AJ243957.1) strains. Only 11 of these 29 amino acids were common for the cherry-adapted $\mathrm{C}$ isolates and different in the non-cherry adapted isolates, and of these 11 amino acids, four were present in the CR isolates as well (Fig. 1).

In order to assess if the PPV-C isolates propagated in its natural host were able to infect Nicotiana species as SwCM, leaf extracts from BY101-infected $P$. avium $\times P$. pseudocerasus 'Colt' plants were used as inoculum for the mechanical handinoculation of $N$. clevelandii and BY181-infected $P$. avium $\times P$. pseudocerasus 'Colt' plants were used for $N$. benthamiana and 
N. clevelandii plants. As a control, both Nicotiana species were also inoculated with an extract of SwCM-infected $N$. clevelandii plants.

At 15 dpi, only the $N$. clevelandii and $N$. benthamiana plants inoculated with SwCM displayed their characteristic symptoms of infection (Fig. 2). All the plants that had been inoculated with either BY101 or BY181 were symptomless. It was not until 21 dpi that $N$. benthamiana plants that had been inoculated with BY181 showed very mild symptoms (Fig. 2A). All the $N$. clevelandii plants remained asymptomatic (data not shown).

Samples from symptomatic upper leaves of $N$. benthamiana and from asymptomatic $N$. clevelandii leaves were collected at $21 \mathrm{dpi}$, and viral accumulation was analyzed. As expected, viral $\mathrm{CP}$ was detected in all the plants that had been inoculated with the control SwCM, as suggested by symptom development. However, CP accumulation analysis confirmed that BY101 and BY181 were not as easily propagated in Nicotiana species (Fig. 2B).

\section{A full-length cDNA clone of PPV-C BY101 is highly infectious in P. avium but only poorly infects other Prunus species.}

A new PPV-C full-length cDNA infectious clone was assembled by replacing most of the viral genome of SwCM with the corresponding cDNA fragments amplified by immunocapture (IC) RT-PCR from leaf tissue of a cherry rootstock infected with the BY101 isolate. This clone was named pICPPV-CaBY101n and its progeny $\mathrm{CaBY} 101 \mathrm{n}$ (Fig. 1).

In order to determine whether this clone was infective in different Prunus species, seedlings of the rootstocks, i.e., P. avium 'Pontavium', P. persica 'GF305', and P. domestica 'Brompton', were inoculated by particle bombardment with the reconstructed pICPPV-CaBY101n clone.

At $10 \mathrm{dpi}$, the first systemic symptoms were observed in most $P$. avium seedlings. In the other species, very mild symptoms appeared only after $14 \mathrm{dpi}$ in a few individuals.

Typically, symptoms in $P$. avium were initially visible on I+2 to I+4 leaves (second and fourth leaves above the youngest

Table 1. Infectivity of SwCM in herbaceous hosts as compared with other C isolates propagated in Nicotiana species

\begin{tabular}{|c|c|c|c|c|}
\hline \multirow[b]{2}{*}{ Species } & \multicolumn{2}{|c|}{ SwCM } & \multirow[b]{2}{*}{$\mathbf{S w C}^{\mathbf{b}}$} & \multirow[b]{2}{*}{$\mathrm{SoC}^{\mathbf{b}}$} \\
\hline & Time symptoms appeared $^{\mathrm{a}}$ & Kind of symptoms & & \\
\hline \multicolumn{5}{|l|}{ Local and systemic infectivity } \\
\hline Nicotiana benthamiana & $\begin{array}{l}\approx 5 \text { to } 8 \text { dpi for upper } \\
\text { noninoculated leaves and } \\
8 \text { to } 11 \text { dpi for inoculated } \\
\text { leaves. }\end{array}$ & $\begin{array}{l}\text { Chlorotic mottling on inocu- } \\
\text { lated leaves and systemic } \\
\text { venial necrosis, stem bend- } \\
\text { ing, and general wilting } \\
\text { leading to plant death at } \approx 15 \\
\text { to } 18 \text { dpi. }\end{array}$ & $\begin{array}{l}\text { Systemic chlorotic mottling } \\
\text { (Crescenzi et al. 1997). } \\
\text { Systemic necrosis with } \\
\text { consequent plant death } \\
\text { (Fanigliulo et al. 2003). }\end{array}$ & $\begin{array}{l}\text { Systemic necrosis with } \\
\text { consequent plant death } \\
\text { (Fanigliulo et al. 2003). }\end{array}$ \\
\hline N. clevelandii & $\begin{array}{l}\approx 10 \text { dpi for inoculated } \\
\text { leaves and } 12 \text { dpi for upper } \\
\text { noninoculated leaves. }\end{array}$ & $\begin{array}{l}\text { Local and systemic necrotic } \\
\text { mottling that does not lead } \\
\text { to plant death. }\end{array}$ & $\begin{array}{l}\text { Local chlorotic and necrotic } \\
\text { lesions followed by } \\
\text { systemic mottling } \\
\text { (Crescenzi et al. 1997). }\end{array}$ & N.d. \\
\hline N. occidentalis & $\begin{array}{l}\approx 8 \text { dpi for inoculated leaves } \\
\text { and } 12 \text { dpi for upper } \\
\text { noninoculated leaves. }\end{array}$ & $\begin{array}{l}\text { Local and systemic necrotic } \\
\text { mottling that does not lead } \\
\text { to plant death. }\end{array}$ & $\begin{array}{l}\text { Systemic chlorotic mottling } \\
\text { (Crescenzi et al. 1997). }\end{array}$ & N.d. \\
\hline \multicolumn{5}{|l|}{ Local infectivity } \\
\hline N. tabacum var. Xhanti & $\approx 5$ to $8 \mathrm{dpi}$ & Local necrotic mottling. & N.d. & N.d. \\
\hline \multicolumn{5}{|l|}{ Not infected ${ }^{c}$} \\
\hline Chenopodium foetidum & - & - & $\begin{array}{l}\text { Not infected (Crescenzi et } \\
\text { al. 1997) }\end{array}$ & N.d. \\
\hline \multirow[t]{2}{*}{$\begin{array}{l}\text { Arabidopsis thaliana } \\
\text { var. Col-0, Ler and Nd-1 }\end{array}$} & - & - & N.d. & $\begin{array}{l}\text { Col-0 and Ler: Not infected } \\
\text { (Decroocq et al. 2006) }\end{array}$ \\
\hline & & & & $\begin{array}{l}\text { Nd-1: Local infection but } \\
\text { resistance to systemic } \\
\text { movement (Decroocq et al. } \\
2006)^{\mathrm{d}}\end{array}$ \\
\hline
\end{tabular}

a Time of symptoms appearance can have slight fluctuations according to the experiment. dpi = days postinoculation.

${ }^{\mathrm{b}}$ Previously published data. N.d. = Not determined for these isolates in previous reports.

${ }^{\mathrm{c}}$ Result based on the lack of symptoms displayed at 21 dpi and the lack of viral accumulation according to immunoblot analyses.

${ }^{\mathrm{d}}$ Results based on reverse transcription-polymerase chain reaction.

Table 2. Infectivity of SwCM in Prunus species

\begin{tabular}{|c|c|c|c|c|c|c|}
\hline Kind of host & Inoculation method & Infectivity $^{\mathrm{a}}$ & Number $^{b}$ & Appearance $^{c}$ & Symptoms & Persistence $^{d}$ \\
\hline \multicolumn{7}{|l|}{ Cherry } \\
\hline $\begin{array}{l}\text { 5-year- old rootstocks (derived } \\
\text { from } P \text {. avium and } P \text {. mahaleb) }\end{array}$ & Particle bombardment & Local & $0 / 8$ & - & - & - \\
\hline Unknown cultivar seedlings & Particle bombardment & Local and systemic & $1 / 6$ & - & - & No \\
\hline $\begin{array}{l}\text { P. avium 'Pontavium' rootstock } \\
\text { seedlings }\end{array}$ & Particle bombardment & Local & $0 / 11$ & - & - & - \\
\hline $\begin{array}{l}\text { P. avium 'Pontavium' rootstock } \\
\text { seedlings }\end{array}$ & $\begin{array}{l}\text { Hand inoculation with extract } \\
\text { of infected } N \text {. clevelandii }\end{array}$ & Local and systemic & $4 / 9$ & $\approx 60 \mathrm{dpi}$ & $\begin{array}{l}\text { Necrotic spots on } \\
\text { single leaves }\end{array}$ & No \\
\hline \multicolumn{7}{|l|}{ Peach } \\
\hline P. persica 'GF305' seedlings & Particle bombardment & Local & $0 / 9$ & - & - & - \\
\hline
\end{tabular}

${ }^{a}$ Coat protein detected by immunoblot analysis.

b Number of systemically infected/number of inoculated plants.

c Time when symptoms appeared. Only two of four systemically infected plants developed symptoms of infection. dpi = days postinoculation.

${ }^{\mathrm{d}}$ Viral persistence after vernalization. 
inoculated leaf). These appeared as focalized veinal chlorosis that did not expand through the leaf and became most evident when the infection was already well established in upper leaves. Veinal chlorosis developed increasingly stronger and brighter in upper leaves, in which it was able to cover entire leaves. Young leaves, despite appearing symptomless, quickly developed strong and distorting symptoms of infection (Fig. 3A).
In $P$. domestica, symptoms were initially visible on $\mathrm{I}+3$ to I+5 and appeared as localized chlorotic foci that tended to fade in time. In upper leaves, veinal but not totally expanding chlorosis and some mottling were also observed. At 21 dpi, leaf distortion was not strong (Fig. 3A).

In $P$. persica, symptoms appeared in single leaves ( +5 or I+7) as a weak and difficult-to-appreciate veinal chlorosis that

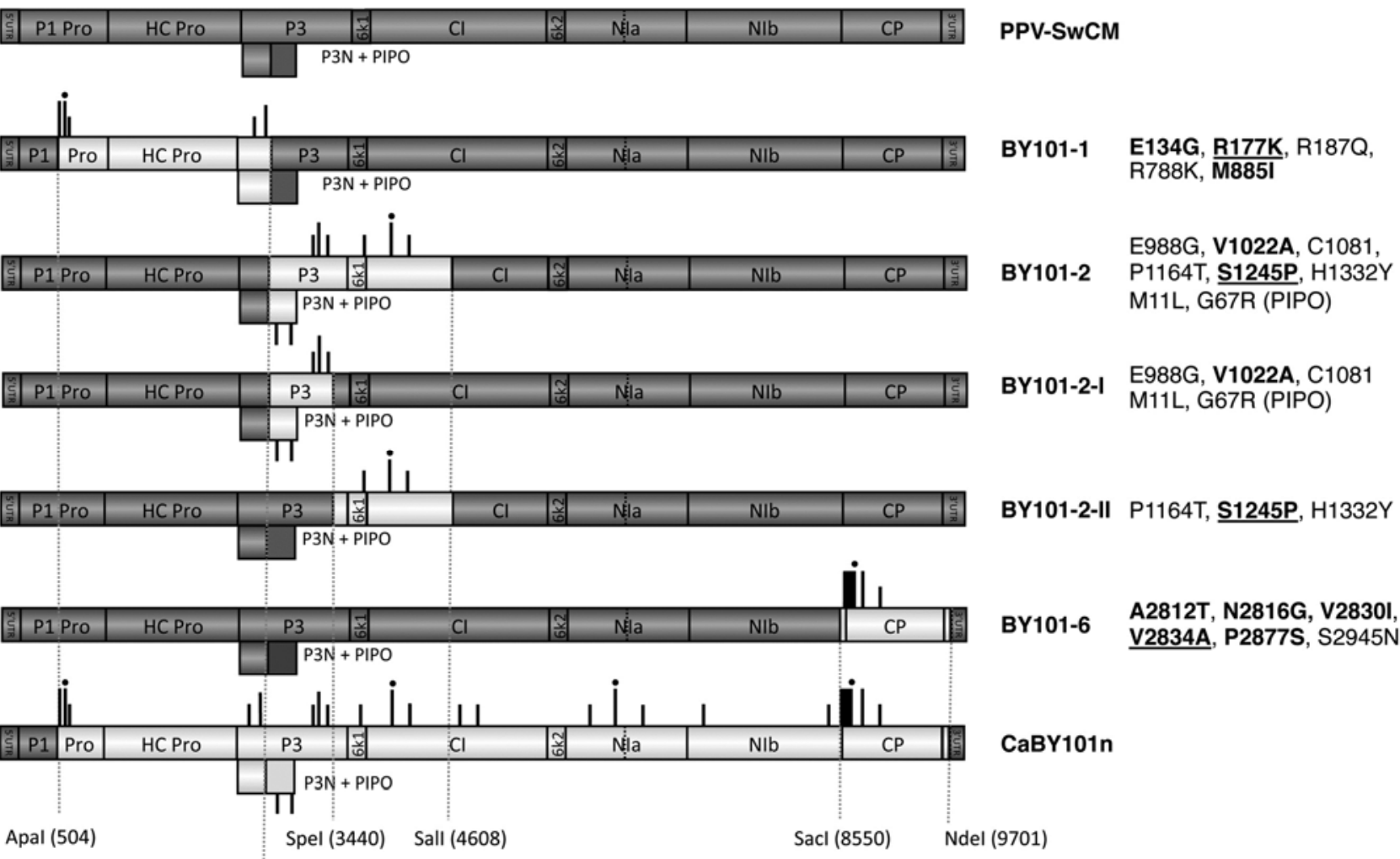

SexAl (2899)

Fig. 1. Schematic representation of full-length cDNA infectious clones. Dark gray boxes represent the different coding sequences and the $5^{\prime}$ and $3^{\prime}$ untranslated region of the SwCM genome. Light gray boxes correspond to cDNA fragments of the BY101 isolate cloned between the indicated restriction sites (dotted gray vertical lines, nucleotide location of the restriction sites are indicated according to the BY101 isolate sequence). Amino acid positions in which isolates BY101 and SwCMp differ are indicated with short vertical bars and are annotated on the right side, beside the name of each pICPPV-C clone. Longer vertical bars and bold amino acid annotations stand for amino acid positions that seem to be specific for the cherry-adapted strain $\mathrm{C}$ isolates. Dots and underlined amino acid annotations show those conserved in cherry-adapted C isolates that are coincident in Plum pox virus (PPV) CR isolates. Intron I from the ST-LS1 gene of tomato (interrupting the P3 cistron) has not been indicated in order to simplify the schemes.
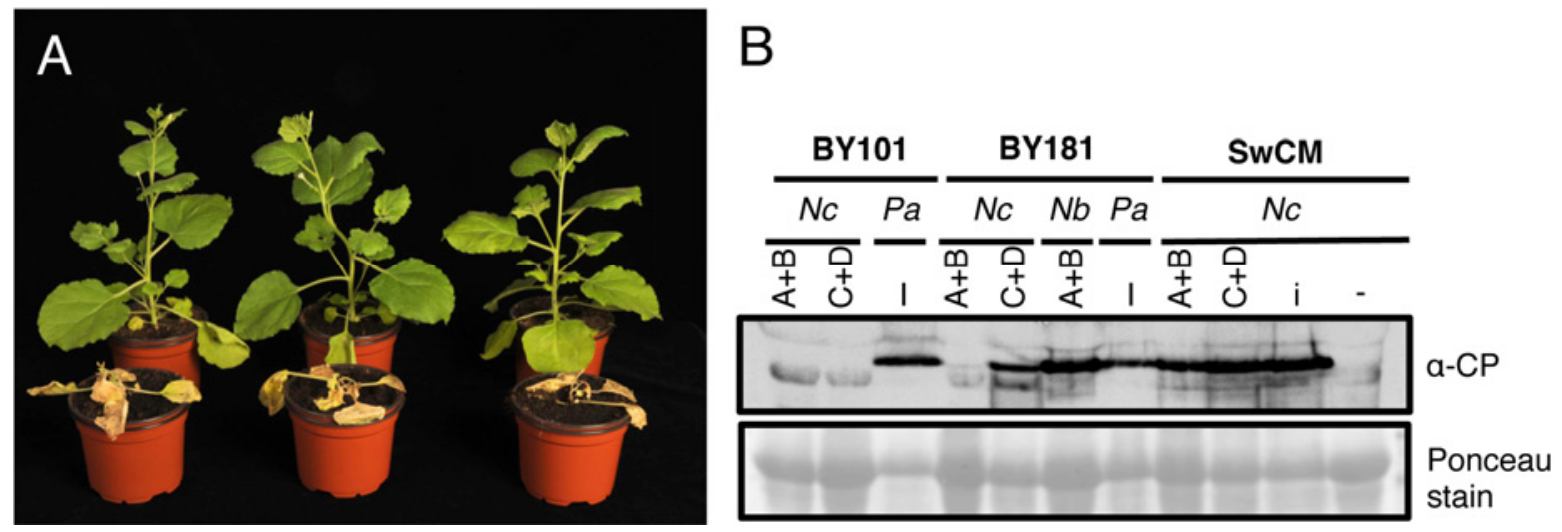

Fig. 2. Infectivity of cherry-adapted isolates BY101 and BY181 as compared with SwCM in Nicotiana species. Four N. clevelandii plants were inoculated with isolates BY181, BY101, or SwCM. Four N. benthamiana plants were inoculated with BY181 or SwCM. A, N. benthamiana plants inoculated with SwCM (front row) or BY181 (back row) at 21 days postinoculation (dpi). B, Viral accumulation at 21 dpi was tested by immunoblot analysis (anti-coat protein serum dilution 1:10,000) on upper leaves of $N$. clevelandii $(\mathrm{Nc})$ or $N$. benthamiana $(\mathrm{Nb})$ plants that had been inoculated using an extract of infected $P$. avium (Pa) (I) in the case of isolates BY101 and BY181 or an extract of infected N. clevelandii (i) in the case of SwCM. Samples consisted of pools of two plants (A+B or C+D). Healthy N. clevelandii tissue was used as a negative control (-). Membrane stained with Ponceau red showing the Rubisco is included as a loading control in the lower panel. 
tended to fade in time and was not accompanied by leaf distortion (Fig. 3A).

The number of infected seedlings and the strength of symptoms at $21 \mathrm{dpi}$ are summarized in Table 3. At this time, viral accumulation in the inoculated and upper leaves was determined by immunoblot analysis (Fig. 3B). Viral CP was detected in the inoculated leaves of all $P$. avium and $P$. domestica seedlings that displayed symptoms at the time of sample collection or later. In most cases, local viral accumulation was higher in $P$. avium than in $P$. domestica. In $P$. persica, not even a faint $\mathrm{CP}$ band could be detected in any of the inoculated plants. Viral accumulation in upper leaves was detected in all symptomatic spots analyzed, but it was lower in the scarce sectors with mild symptoms of $P$. domestica and $P$. persica than in the large areas with severe symptoms of $P$. avium.
Table 3. Evaluation of symptoms in Prunus seedlings of different species inoculated with pICPPV-CaBY101n

\begin{tabular}{lcc}
\hline Species & No. seedlings $^{\mathbf{a}}$ & Level of symptoms $^{\mathbf{b}}$ \\
\hline Prunus avium & $7 / 8$ & $0(1), 2(1), 4(6)$ \\
P. domestica & $2 / 8$ & $0(6), 1(1), 2(1)$ \\
P. persica & $3 / 8$ & $0(5), 1(3)$ \\
\hline
\end{tabular}

${ }^{a}$ Number of symptomatic/number of inoculated seedlings. Symptoms were evaluated at 21 days postinoculation.

b The level of symptoms was evaluated for each seedling. $0=$ absence of symptoms, 1 = light veinal chlorosis in one or two leaves, difficult to appreciate, $2=$ evident veinal chlorosis in three or more leaves, $3=$ veinal chlorosis and rings in half of leaves. $4=$ most leaves with veinal chlorosis and rings including deformation of leaves, $5=$ all leaves show veinal chlorosis and rings with important deformations. The number of seedlings displaying the symptom level are indicated in parentheses.
A

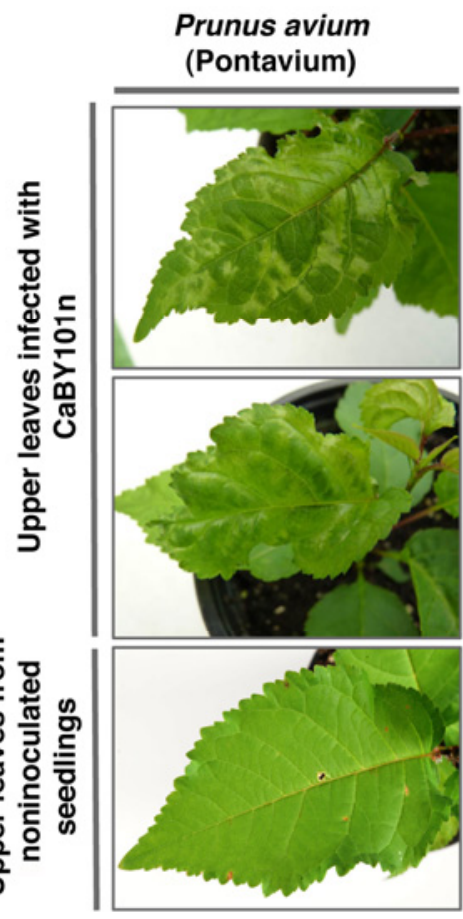

B
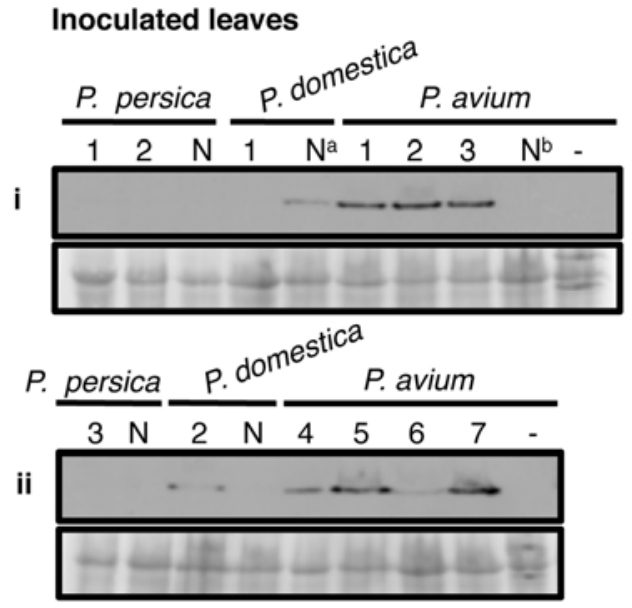

Prunus domestica (Brompton)

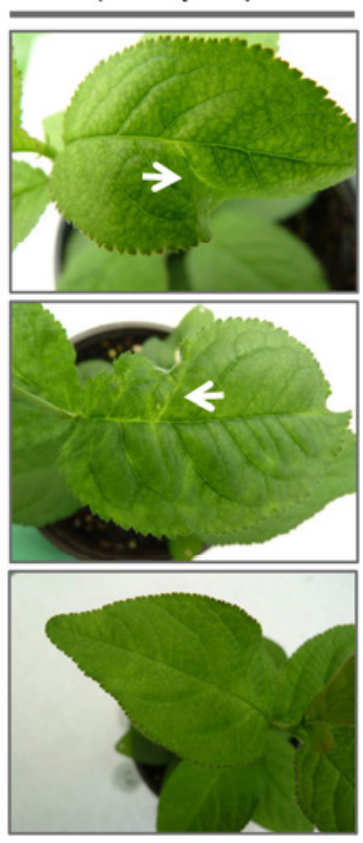

Prunus persica

(GF305)

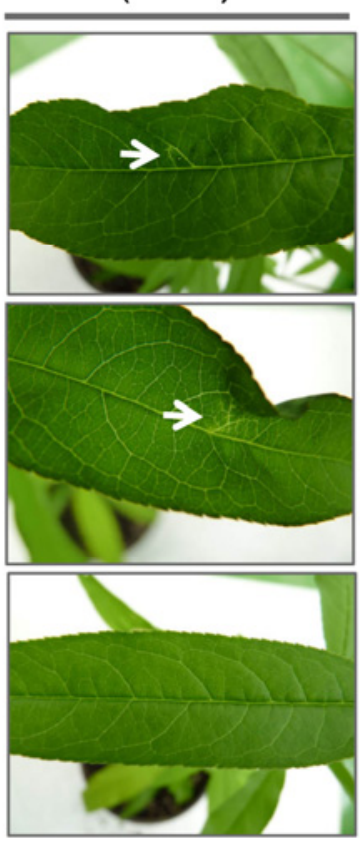

\section{Upper leaves}
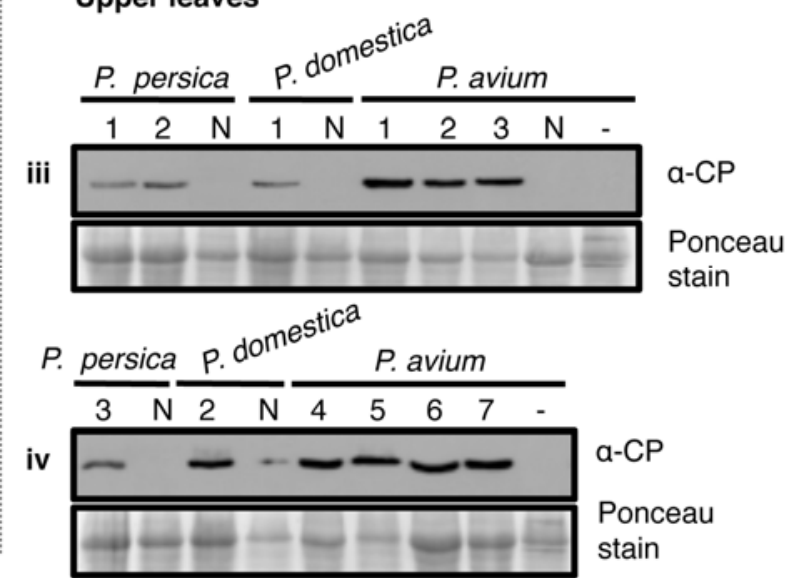

stain

a-CP

Ponceau

stain

Fig. 3. Infectivity of CaBY101n in Prunus spp. Eight seedlings of each species were inoculated with pICPPV-CaBY101n. A, Symptoms observed in upper leaves (first two rows) of Prunus avium ('Pontavium'), P. domestica ('Brompton'), and P. persica ('GF305') as compared with healthy leaves of noninoculated plants (third row) at 22 days postinoculation (dpi). Symptoms in P. domestica and P. persica are indicated with white arrows. B, Viral accumulation assessed at 22 dpi by immunoblot analysis (anti-coat protein serum dilution 1:100,000) on leaf discs covering the shot area of inoculated leaves (i and ii) and symptomatic areas (or equivalent areas in the cases in which no symptoms were observed) of upper leaves (iii and iv). Lanes 1 to 7: Individually analyzed seedlings; lane N: Asymptomatic $P$. avium seedling and pools of asymptomatic seedlings of $P$. domestica or $P$. persica; lane $\mathrm{N}^{\mathrm{a}}$ : one of the seedling samples included in this pool displayed systemic symptoms at 26 dpi. Membrane stained with Ponceau red showing the Rubisco is included as a loading control in the lower panels. 
A genomic region coding for the $\mathrm{C}$-terminus of $\mathrm{P3}$, part of P3N-PIPO, 6K1, and the N-terminus of CI contains genetic determinants involved in the alternative adaptation of PPV-C to $N$. benthamiana and $P$. avium.

According to the results described above, SwCM, which is highly virulent in $N$. benthamiana, is unable to establish a systemic and persistent infection in $P$. avium. On the contrary, CaBY101n causes a strong systemic infection in $P$. avium but its parental isolate does not induce noticeable symptoms in $N$. benthamiana. Thus, we hypothesized the SwCMp isolate could have introduced mutational changes in its genome during the serial passages in Nicotiana species to which it had been subjected, which could have resulted in a loss of genetic determinants required to infect $P$. avium systemically in an efficient way.

To test this hypothesis, three clones-pICPPV-CBY101-1, pICPPV-CBY101-2, and pICPPV-CBY101-6 (viral progeny denominated BY101-1, BY101-2, and BY101-6, respectively), which exchanged the most divergent regions between isolates BY101 and SwCM (nucleotides 504 to 2,899, 2,900 to 4,608, and 8,550 to 9,701, respectively) (Fig. 1) and were constructed as intermediate steps in the assembly of pICPPV-CaBY101nwere inoculated by particle bombardment into $P$. avium and $N$. benthamiana plants.

In $P$. avium, the first symptoms were detected on upper leaves of one of the seedlings that had been inoculated with pICPPVC-BY101-2 as soon as $11 \mathrm{dpi}$. At 19 dpi, eight of the 12 seedlings inoculated with this clone were also displaying symptoms of infection (Supplementary Table S1), while all 12 seedlings that had been inoculated with each of the other clones remained symptomless. In this experiment, the symptoms observed in $P$. avium were similar to those provoked by CaBY101n or slightly milder (Fig 4A).
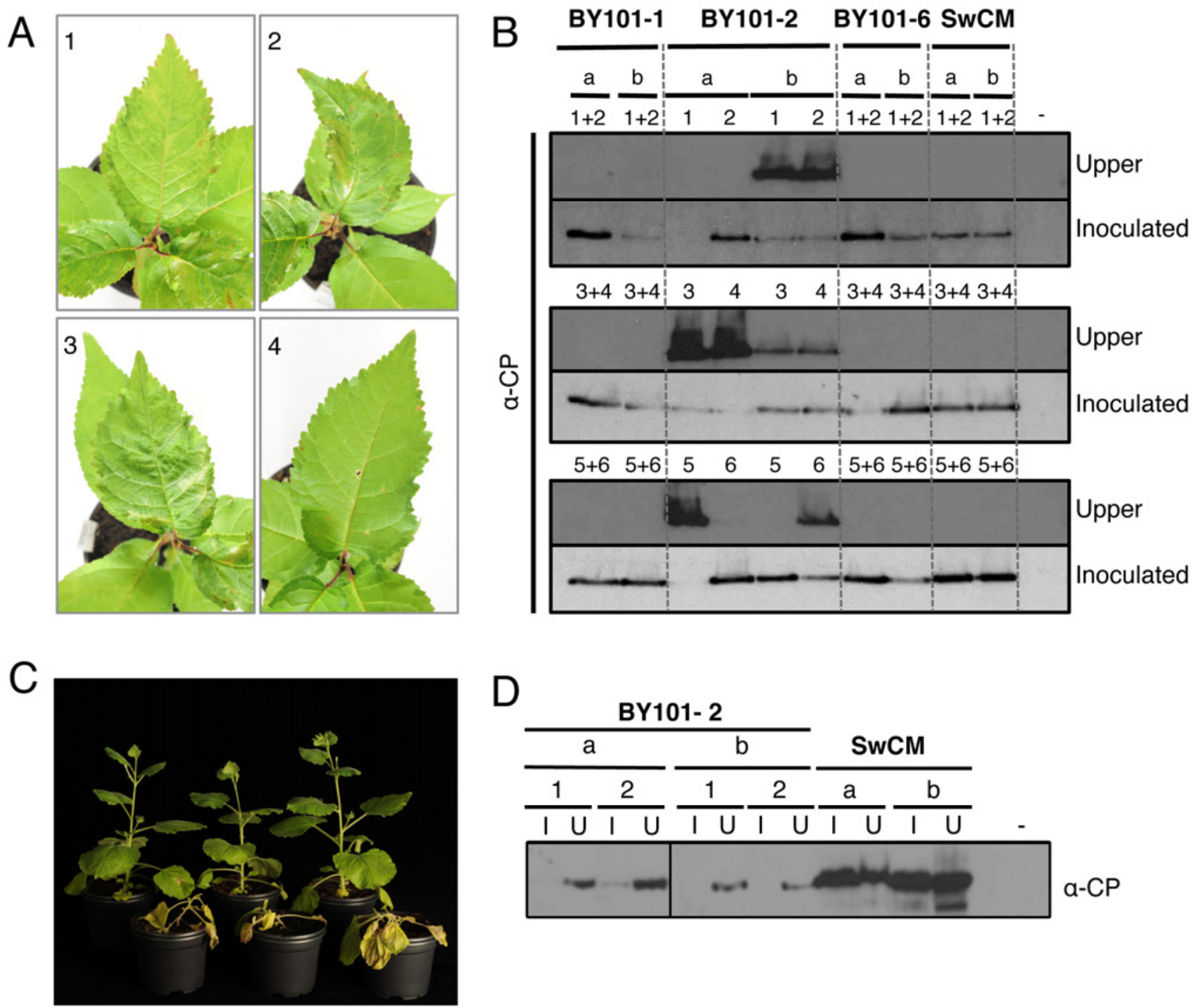

$D$

BY101- 2

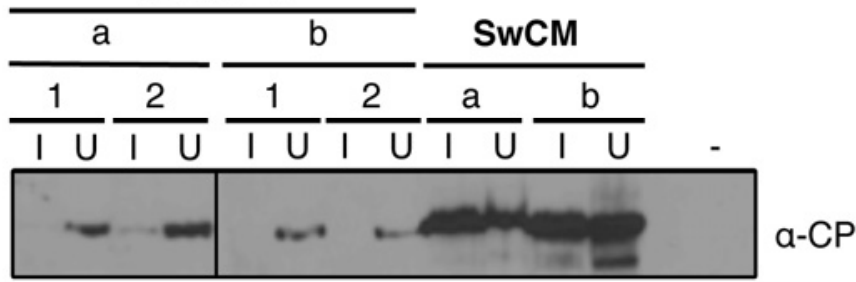

Fig. 4. Infectivity of BY101-1, BY101-2, BY101-6, and SwCM in Prunus avium seedlings and infectivity of BY101-2 and SwCM in Nicotiana benthamiana. Twelve Prunus seedlings and four $N$. benthamiana plants were inoculated biolistically, with each clone using two different DNA inocula for each (a and b). A, Photos 1, 2, and 3 show symptoms of systemic infection caused by BY101-2 at 21 days postinoculation (dpi). Photo 4 shows an upper leaf from a nonsystemically infected seedling inoculated with pICPPV-SwCM at $21 \mathrm{dpi}$. B, Samples from entire inoculated leaves (lower panel of each pair of blots) and from second and third leaves above the inoculated ones (upper panel of each pair of blots) were collected at 23 and 25 dpi, respectively, and were assessed by immunoblot analysis (anti-coat protein [CP] serum dilution 1:100,000). Samples from seedlings inoculated with pICPPV-CBY101-1, pICPPV-CBY101-6, and SwCM (asymptomatic) were analyzed in pools of two plants, while samples coming from seedlings inoculated with pICPPV-CBY101-2 (either symptomatic or asymptomatic) were analyzed individually. A healthy $P$. avium sample was used as a negative control (-). C, Symptoms induced by SwCM (front row) and BY101-2 (back row) at 15 dpi in N. benthamiana. D, Viral accumulation assessed by immunoblot analysis on inoculated (I) and upper (U) leaves of four plants inoculated with pICPPV-CBY101-2 and two plants inoculated with pICPPV-SwCM (anti-CP serum dilution 1:100,000). A healthy N. benthamiana sample was used as a negative control (-). 


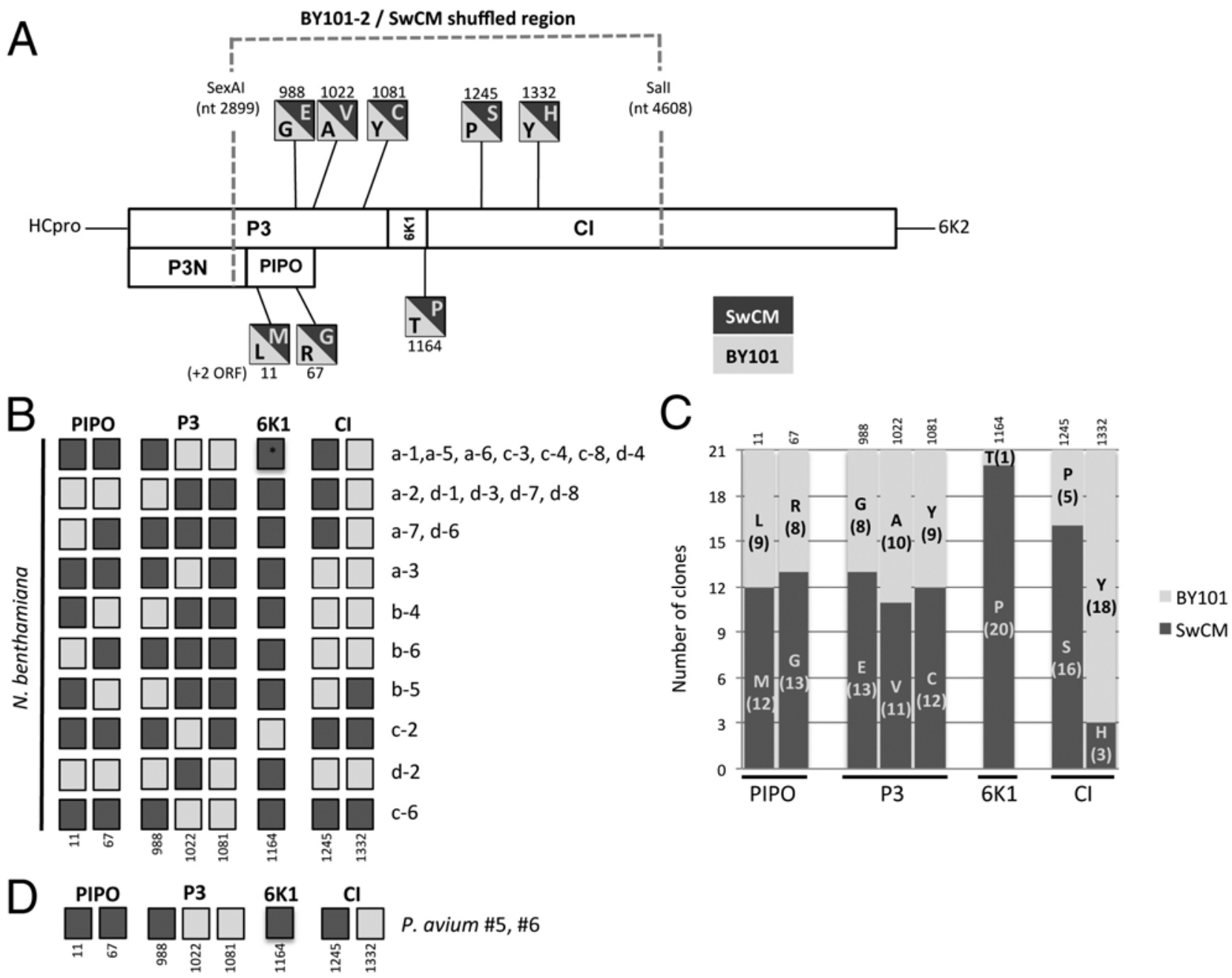

Fig. 5. Identification of genetic determinants affecting the infectivity in Prunus avium and Nicotiana benthamiana of BY101-2 and SwCM through DNA shuffling. A, DNA shuffled-library scheme. cDNA sequences between restriction sites SexAI (nt 2,899) and SalI (nt 4,608) from BY101 and SwCM were shuffled and cloned into the pICPPV-SwCM backbone. White rectangles represent Plum pox virus (PPV) P3, P3N+PIPO, 6K1, and CI (cylindrical inclusion) cistrons. Shaded boxes represent amino acids in which BY101 (light gray) and SwCM (dark gray) differ. Amino acid positions in the PPV polyprotein are indicated above or below each box. B, Genotype of the 21 individual clones infecting upper leaves of four $N$. benthamiana plants (a to d) that were sequenced. Light gray and dark gray boxes represent amino acids from BY101 and SwCM, respectively. Each row corresponds to a different haplotype. Amino acid positions within the PPV polyprotein are indicated below each column. (*An alternative mutation in the same codon giving rise to P1164 was observed in two clones, a-1 and a-5, from a single plant). C, Graphic scheme showing the proportion of selected amino acids from either BY101-2 or SwCM in each amino acid position in the 21 individually sequenced clones. Amino acid positions within the PPV polyprotein are indicated above each column. D, Viral clone that was selected in two independent experiments among the pool of 139 shuffled clones in P. avium (seedlings \#5 and \#6, respectively). Light gray boxes represent amino acids from BY101. Dark gray boxes represent amino acids from SwCM. Amino acid positions in the PPV polyprotein are indicated below each box.

Table 4. Amino acid changes introduced during serial passages of BY101-2 in Nicotiana benthamiana

\begin{tabular}{|c|c|c|c|c|c|c|c|}
\hline \multirow[b]{2}{*}{ Plants $^{\mathrm{a}}$} & \multicolumn{3}{|c|}{ Sequences of IC-RT-PCR products ${ }^{b}$} & \multicolumn{4}{|c|}{ Sequences of individual clones ${ }^{b}$} \\
\hline & P3 & 6K1 & CI & No. clones & $\mathbf{P 3}$ & 6K1 & CI \\
\hline A1 & & & & & & & - \\
\hline Passage 1 & $\mathrm{~K}_{993 \mathrm{R}^{\mathrm{c}}}$ & $\mathrm{T} 1164 \mathrm{P}^{\mathrm{d}}$ & $\mathrm{S} 1169 \mathrm{~N}^{\mathrm{d}}$ & $\begin{array}{l}3 \\
1\end{array}$ & - & T1164P & - \\
\hline Passage 4 & $\begin{array}{l}\text { K993R }^{\mathrm{c}} \\
\text { K1063E }\end{array}$ & - & $\mathrm{S} 1169 \mathrm{~N}$ & 4 & $\begin{array}{l}\text { K993R, } \\
\text { K1063E }\end{array}$ & - & S1169N \\
\hline $\begin{array}{l}\text { A2 } \\
\text { Passage } 4 \\
\text { B1 }\end{array}$ & A1040T & - & $\mathrm{D} 1171 \mathrm{~N}$ & 4 & A1040T & - & $\mathrm{D} 1171 \mathrm{~N}$ \\
\hline $\begin{array}{l}\text { Passage } 4 \\
\text { B2 }\end{array}$ & Q1054R & $\mathrm{T} 1164 \mathrm{P}^{\mathrm{d}}$ & $\mathrm{D} 1171 \mathrm{~N}$ & 4 & Q1054R & - & $\mathrm{D} 1171 \mathrm{~N}$ \\
\hline Passage 4 & - & $\mathrm{T} 1164 \mathrm{P}^{\mathrm{d}}$ & $\mathrm{D} 1171 \mathrm{~N}^{\mathrm{d}}$ & $\begin{array}{l}1 \\
3\end{array}$ & $\begin{array}{l}- \\
-\end{array}$ & $\begin{array}{l}\text { T1164P } \\
\text { T1164P }\end{array}$ & $\begin{array}{l}\mathrm{D} 1171 \mathrm{~N} \\
-\end{array}$ \\
\hline
\end{tabular}

a The initially infected plants A1, A2, B1, and B2 were subjected to four serial plant-to-plant passages.

${ }^{b}$ The immunocapture reverse transcription-polymerase chain reaction (IC-RT-PCR) products were cloned in pUC19, and four of the resulting plasmids of each cloned IC-RT-PCR were analyzed to check the sequence of individual viruses. - indicates no mutations in the indicated coding sequences.

${ }^{\mathrm{c}}$ Double peak in P3 that coexists with the original sequence of BY101-2, which does not affect PIPO.

${ }^{\mathrm{d}}$ Double peaks in 6K1 or CI that coexist with the original sequence of BY101-2. 
According to immunoblot analyses, all the clones (BY101-1, BY101-2, BY101-6, and SwCM) were able to infect $P$. avium locally and accumulated similar amounts of virus (Fig 4B). Thus, none of the chimeras appeared to have any infectivity advantage over SwCM at the local level in cherry. However, in agreement with the symptoms scrutiny, CP accumulation in upper leaves was detected only in the seedlings inoculated with the chimera BY101-2 (Fig. 4B). The infection of BY101-2 persisted after at least two cycles of vernalization (data not shown). These data demonstrate that the 2,940- to 4,574-nt region, coding for the C-termini of the P3 part of P3N-PIPO, $6 \mathrm{~K} 1$, and the $\mathrm{N}$-terminus of $\mathrm{CI}$ (cylindrical inclusion) of BY101, is able to confer SwCM the ability to establish a systemic infection in cherry.

$N$. benthamiana plants inoculated with clones pICPPVCBY101-1 and pICPPV-CBY101-6 started to display systemic symptoms of infection at $6 \mathrm{dpi}$. These were phenotypically identical to those caused by SwCM (Table 1). In contrast, plants inoculated with pICPPV-CBY101-2 remained symptomless at this time and only one of four plants displayed a mild mosaic on upper leaves at $21 \mathrm{dpi}$ (Fig. 4C). Immunoblot analysis showed that, although both symptomatic and asymptomatic $N$. benthamiana plants were infected, viral accumulation was much lower both in inoculated and upper leaves of BY101-2-infected plants than in plants infected with SwCM (Fig. 4D).

Altogether, these results suggest that sequences in the C-P3 (PIPO)/6K1/N-CI region that facilitate the systemic spread of PPV-C in $P$. avium interfere with virus amplification in $N$. benthamiana, even in the inoculated leaves.

\section{Single amino acid changes within or surrounding the NIapro cleavage site between $6 \mathrm{~K} 1$ and $\mathrm{CI}$ promote the alternative adaptation of BY101-2 to $N$. benthamiana or P. avium.}

According to the sequence analysis, clones BY101-2 and SwCM differ in the C-P3(PIPO)/6K1/N-CI region in $27 \mathrm{nt}$ positions, giving rise to eight amino acid differences (Fig. 1). Given that variants misfit to $N$. benthamiana and $P$. avium appear to have defects in different steps of the infection process, different genetic determinants within this region could be involved in the adaptation to each host. Since any combination of nucleotides could be necessary, a cDNA library containing 139 recombinant clones in which the sequences of BY101-2 and SwCM had been shuffled at random, was constructed in the pICPPV-SwCM backbone (Fig. 5A). The shuffled library was sequenced to check that double peaks appeared in all the polymorphic nucleotide positions, and a PCR product of the shuffled region was also sequenced to check that the variability was maintained during an amplification process. Additionally, 45 individual clones from the library were totally or partially sequenced within the shuffled region to check the variability of the clones. It was expected that after the inoculation of the pool of recombinant-shuffled clones, only the viruses containing the adequate sequence combinations would be positively selected by each host.

Adaptation to $\mathrm{N}$. benthamiana. $N$. benthamiana plants were biolistically inoculated with the pool of shuffled clones. At 10 dpi, all the $N$. benthamiana plants displayed strong systemic symptoms of infection, but only one of them displayed the necrotic wilting typical for SwCM. Upper leaves were collected and the genome of the viral progeny infecting these leaves was analyzed by IC-RT-PCR followed by sequencing of the shuffled region. We focused our analysis in the positions with amino acid polymorphisms, expecting that changes in protein sequences, rather than silent nucleotide substitutions, would more probably result in phenotypic alterations.
In most of the amino acid positions in which SwCM and BY101-2 differed, the sequenced RT-PCR tests revealed that no selection had taken place, as double peaks appeared in the sequence. The only exception was the nucleotide position that affects the codon that is translated into amino acid T/P 1164 (BY101-2/SwCM) in 6K1, where P1164 was preferentially selected in four of six plants, including one plant in which a spontaneous mutation in the third nucleotide of the same codon was introduced. In the other two cases, double peaks were obtained in all expected positions.

To check the amino acid composition of individual viruses infecting these $N$. benthamiana plants, the IC-RT-PCR products from different plants were cloned and a total number of 21 clones were sequenced. Ten different amino acid haplotypes were found in viruses infecting upper leaves (Fig. 5B). Three of the haplotypes were detected repeatedly, not only inside one plant, but also in different plants, although some of the clones of the same haplotype were not identical at the nucleotide level. In most of the polymorphic positions, a clear selection had not taken place. However, 20 of the 21 sequenced clones contained $\mathrm{P} 1164$ in $6 \mathrm{~K} 1$, suggesting that the presence of this amino acid

\begin{tabular}{|rrrc|}
\hline Mutant & P3 & 6K1 & Cl \\
\hline $\mathrm{P}_{1164}$ & & $\mathrm{~T} 1164 \mathrm{P}$ & \\
\hline $\mathrm{N}_{1169}$ & & & $\mathrm{~S} 1169 \mathrm{~N}$ \\
\hline $\mathrm{R}_{1054} \mathrm{~N}_{1171}$ & $\mathrm{Q} 1054 \mathrm{R}$ & $\mathrm{D} 1171 \mathrm{~N}$ \\
\hline $\mathrm{N}_{1171}$ & & $\mathrm{D} 1171 \mathrm{~N}$ \\
\hline $\mathrm{R}_{1054}$ & $\mathrm{Q} 1054 \mathrm{R}$ & \\
\hline
\end{tabular}
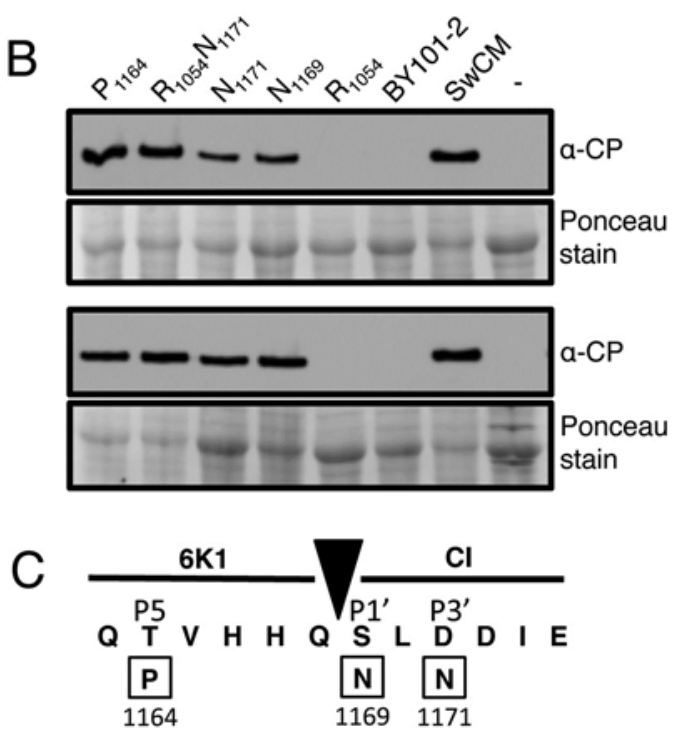

Fig. 6. Adaptation of BY101-2 to Nicotiana benthamiana through serial passages. A, Clones containing mutations that had been introduced in the BY101-derived sequence of BY101-2 during the serial passages. Left column shows the name of the mutants. Columns P3, 6K1, and CI show the mutations that have been introduced for each mutant. B, Viral accumulation assessed by immunoblot analysis (anti-coat protein serum dilution $1: 100,000)$ on upper leaves of $N$. benthamiana at 10 days postinoculation. Each sample consists of an individual plant inoculated with the aboveindicated mutant. A healthy $N$. benthamiana sample was used as a negative control (-). Membrane stained with Ponceau red showing the Rubisco is included as a loading control. C, NIapro recognition and cleavage site (black arrow) between 6K1 and CI. Amino acid changes within or surrounding this site are shown in boxes under the BY101-2 amino acid sequence, including their position in the Plum pox virus polyprotein below each box. Relative positions (P5, $\mathrm{P}^{\prime}$, and $\mathrm{P} 3^{\prime}$ ) according to the NIapro cleavage site are indicated. 
positively affects viral fitness in $N$. benthamiana. Surprisingly, Y1332 from the cherry-adapted BY101-2 had been selected in 18 of the 21 clones (Fig. 5C), despite appearing in similar amounts as $\mathrm{H} 1332$ in the sequence chromatograms of the PCR fragment amplified from the shuffled cDNA library before inoculation.

The significance of the $6 \mathrm{~K} 1 \mathrm{P} 1164$ residue in the adaptation of the virus to $N$. benthamiana was also tested by subjecting the viral progeny of plants infected with the pure BY101-2 clone to four serial passages.

Although the symptoms that were initially displayed by these plants were very mild at the most (Fig 4C), a notable strengthening of the symptoms was observed after just one passage (data not shown). When the sequence of the viral progeny from the fourth passage of all plants (and the first passage of one of them) was determined, it was observed that several mutations affecting not only the $6 \mathrm{~K} 1$ but also the P3 and CI coding sequences, had been introduced (Table 4).

To check if the mutations leading to these amino acid changes had a direct positive effect on viral fitness, mutants containing the most prevalent combinations were engineered in the pICPPV-CBY101-2 backbone (Fig. 6A) and were inoculated, as well as pICPPV-CBY101-2 and pICPPV-SwCM, onto $N$. benthamiana plants. At $10 \mathrm{dpi}$, plants inoculated with mutants $\mathrm{P}_{1164}, \mathrm{~N}_{1169}, \mathrm{R}_{1054} \mathrm{~N}_{1171}$, and $\mathrm{N}_{1171}$ and plants inoculated with pICPPV-SwCM displayed strong symptoms of infection, being necrotic only in the case of SwCM. Viral accumulation analyses revealed that at this time, all the symptomatic mutants had achieved accumulation levels that were similar to those of
SwCM (Fig 6B) without introducing additional mutations in the BY101-derived region (data not shown).

Plants inoculated with mutant $\mathrm{R}_{1054}$ and pICPPV-CBY101-2 did not start to display mild symptoms until 21 dpi. The BY101derived region of the virus progeny of these plants was amplified and sequenced at this time. The sequence of the BY101-2 progeny showed double peaks giving rise again to the amino acid changes T1164P in $6 \mathrm{~K} 1$ and $\mathrm{S} 1169 \mathrm{~N}$ and $\mathrm{D} 1171 \mathrm{~N}$ in CI. Although no additional mutations were detected in the sequenced region of the progeny of mutant $\mathrm{R}_{1054}$, symptoms became stronger in plants inoculated with the $\mathrm{R}_{1054}$-infected tissue, and double peaks generating mutations $\mathrm{S} 1169 \mathrm{~N}$ and D1171N appeared while maintaining the Q1054R mutation.

Interestingly, P1164 is present in isolate SwC and N1169 is present in isolate $\mathrm{SoC}$, suggesting that these amino acids might contribute to the adaptation of PPV-C isolates to $N$. benthamiana. Moreover, both P1164 and N1169 are located within the recognition site of the protease NIapro, placed between $6 \mathrm{~K} 1$ and CI (positions P5 and P1') and N1171 is located nearby, at position P3' (Fig. 6C).

These results, together with the preferential selection of P1164 in the competition between shuffled clones, suggest that the adaptation to $N$. benthamiana would need a modification of the NIapro cleavage site between $6 \mathrm{~K} 1$ and $\mathrm{CI}$ through alternative nonsilent mutations.

Reestablishment of the systemic movement capacity in $\mathrm{P}$. avium. P. avium seedlings were challenged with the pool of shuffled clones in two independent experiments for which different DNA bullets were prepared. In these experiments, a

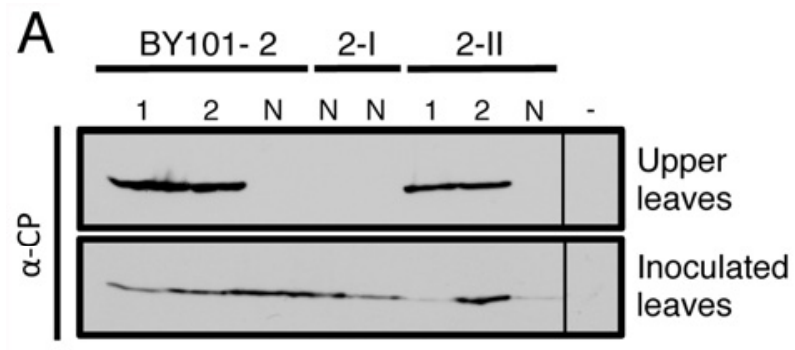

B
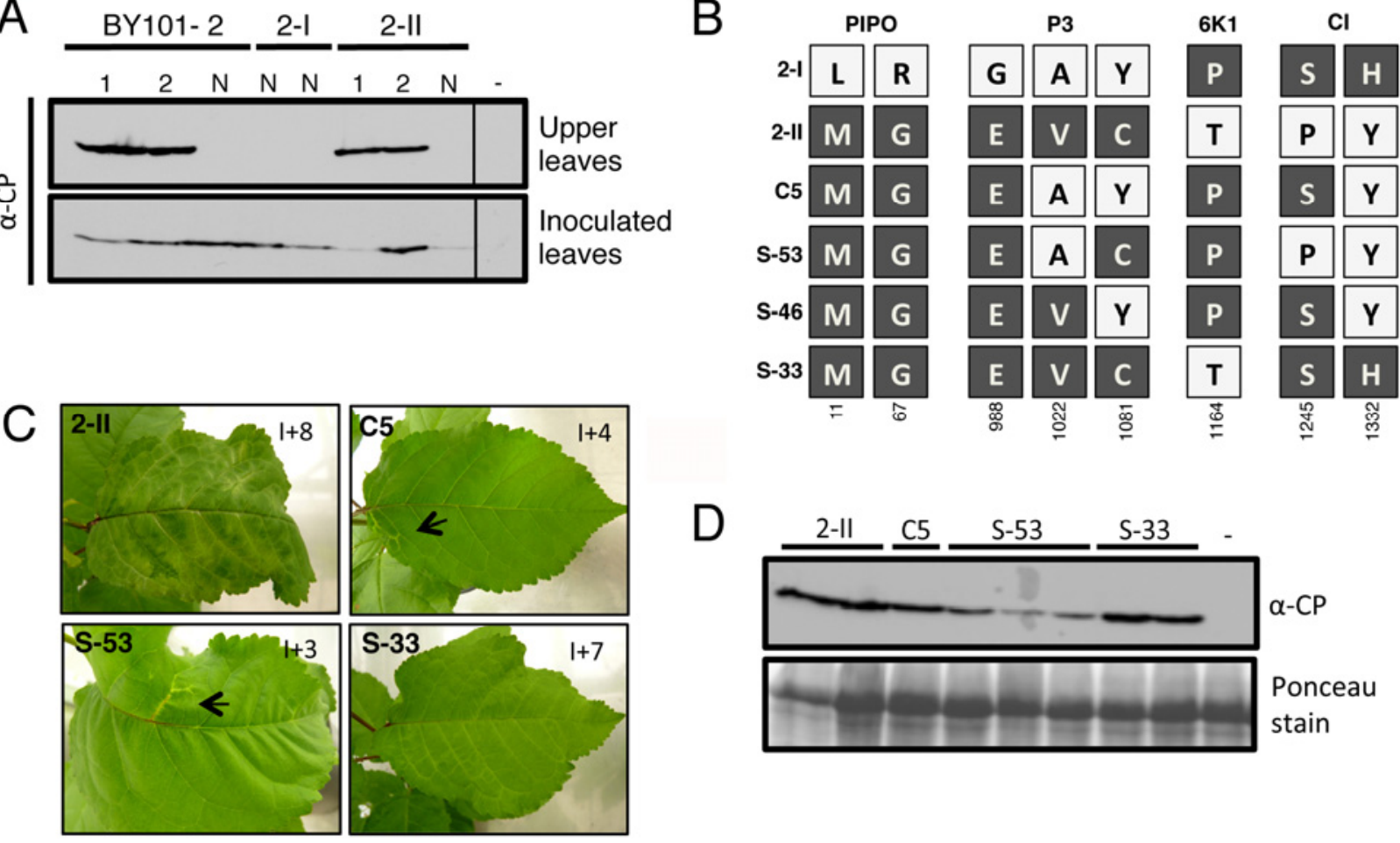

Fig. 7. Infectivity of BY101-SwCM recombinant clones in Prunus avium. A, Viral accumulation assessed by immunoblot analysis (anti-coat protein [CP] serum dilution 1:100,000) on inoculated leaves (lower panel) and upper leaves (upper panel) of $P$. avium seedlings challenged with clones pICPPV-CBY101-2, pICPPV-BY101-2-I, and pICPPV-BY101-2-II at 21 days postinoculation (dpi). Symptomatic seedlings (1 and 2) were individually analyzed. Asymptomatic seedlings $(\mathrm{N})$ were analyzed as pools of two plants. A sample from a healthy noninoculated seedling was used as a negative control (-). B, Amino acid combinations in clones BY101-2-I, BY101-2-II, C5, S-53, S-46, and S-33, constructed in the pICPPV-SwCM backbone. Amino acids coming from SwCM and BY101 are represented in dark and light gray boxes, respectively. Amino acid positions in the Plum pox virus polyprotein are indicated at the bottom of each column. C, Examples of symptoms on upper leaves of $P$. avium seedlings inoculated with clones BY101-2-II, C5, S-53, and S-33 at 30 dpi. The leaf position relative to the inoculated leaves is indicated in each picture. Black arrows indicate the localized symptoms caused by clones C5 and S-53. D, Viral accumulation on symptomatic areas of upper leaves from seedlings infected with clones BY101-2-II, C5, S-53, and S-33, assessed by immunoblot analysis (anti-CP serum dilution 1:100,000) at 30 dpi. Samples from symptomatic seedlings were individually analyzed. A sample from a healthy noninoculated seedling was used as a negative control (-). Membrane stained with Ponceau red showing the Rubisco is included as a loading control in the lower panel. 
very mild and localized veinal chlorosis appeared on a small area of an upper noninoculated leaf of two Prunus seedlings at 25 and $30 \mathrm{dpi}$, respectively. The symptoms of infection did not expand through the leaves in which they were observed and did not progress towards the upper ones. The symptomatic areas were collected and were subjected to IC-RT-PCR followed by sequencing.

In both experiments, the only viral genotype that was positively selected contained a combination of amino acids in which those belonging to BY101-2 were only present in the P3 (A1022, Y1081) and CI (Y1332) coding sequences (Fig. 5D). It might be important to highlight that none of the 45 of 139 individual shuffled clones forming part of the library that were totally or partially sequenced contained this precise genotype.

Thus, this result initially appeared to suggest that neither PIPO nor 6K1 were essential for restoring the systemic movement capacity in $P$. avium. Given this result, two additional clones pICPPV-CBY101-2-I and pICPPV-CBY101-2-II (Fig. 1 ), which separated the P3 and CI cistrons that seemed to be involved in this process, were constructed.

Clones pICPPV-CBY101-2, pICPPV-CBY101-2-I, and pICPPV-CBY101-2-II (viral progeny denominated BY101-2-I and BY101-2-II, in the last two cases) were each inoculated onto $P$. avium seedlings. Although no significant differences were observed in the viral accumulation levels of the leaves inoculated with any of the three clones, only BY101-2 and BY101-2-II were able to infect upper leaves. Both chimeras caused similar symptoms, but viral accumulation of BY101-2II on the systemically infected leaves appeared to be slightly lower (Fig. 7A).

The last results showed that the BY101-derived region of BY101-2-II (sequence specificities in 6K1 and CI) contains genetic determinants able to restore into $\mathrm{SwCM}$ the systemic movement in P. avium. However, the fact that the BY101-2-II accumulation level was lower than that of BY101-2 (Fig. 7A) and the selection of a clone with BY101-derived P3 sequence in the shuffling competition (Fig. 5D) suggested that, indeed, genetic determinants in the $\mathrm{P} 3$ cistron could also be relevant. If this were the case, a clone with the genotype of the virus that was selected among the pool of shuffled clones should be able to reach higher accumulation levels than BY101-2-II when inoculated alone and not being part of a large pool. Thus, clone C5 was constructed to test this hypothesis (Fig. 7B).

At the same time, the infectivity of other shuffled clones from the library (S-53, S-46, and S-33) that had been individually sequenced was tested (Fig. 7B). S-53 and S-46 conserved the residue Y1332 in CI-like clones BY101-2, BY101-2-II, and $\mathrm{C} 5$ but had different amino acid combinations in P3. Clone $\mathrm{S}-33$ was also inoculated in order to determine if the $6 \mathrm{~K} 1 \mathrm{pep}-$ tide, which was directly involved in the adaptation to $N$. benthamiana, had any relevance in the reestablishment of the systemic movement capacity in $P$. avium.

Thus, $P$. avium seedlings were challenged with clones BY101-2-II, C5, S-53, S-46, and S-33. At 30 dpi, most seedlings inoculated with BY101-2-II displayed the expected strong expanding symptoms (similar to those described for BY101-2). The infectivity of clones C5 and S-53 appeared to be lower than that of BY101-2-II, but some seedlings inoculated with these clones displayed symptoms consisting of weak and localized veinal chlorosis. Surprisingly, some seedlings inoculated with clone S-33 also displayed very mild symptoms, sometimes difficult to appreciate, which, in contrast to those of C5 and S-53, expanded through a large area of the leaf. Moreover, symptoms caused by BY101-2-II and S-33 reached upper leaves than those of S-53 and C5 (Fig. 7C).

Viral accumulation in symptomatic areas of upper leaves was found to be the highest in the case of clones 2-II and S-33
(Fig. 7D). Although S-46 was not infective in this experiment, it caused symptoms similar to C5 and S-53 and also low accumulation levels in a single seedling in another experiment.

The identity of the infecting viruses was corroborated by ICRT-PCR followed by sequencing, and no additional mutations were detected in the analyzed region (data not shown).

Thus, although the CI and P3 coding sequences contain genetic determinants that can allow the reestablishment of the systemic movement in $P$. avium even with $\mathrm{P}$ in position 1,164 in $6 \mathrm{~K} 1$, the $\mathrm{P} 1164 \mathrm{~T}$ substitution in $6 \mathrm{~K} 1$ is the main contributor to the reestablishment of the systemic movement capacity of SwCM in $P$. avium.

\section{DISCUSSION}

Whereas some plant viruses have a very restricted host range, others are able to infect a large number of plant species (Hull 2002). The host range of PPV is very wide, including natural woody hosts of the genus Prunus and experimental herbaceous hosts such as A. thaliana and Nicotiana spp. However, the adaptation of some PPV isolates to specific hosts has resulted in the inability to efficiently infect other plant species (Salvador et al. 2008). PPV isolates of the $\mathrm{C}$ strain show pathogenicity features quite different from those of other PPV strains (Crescenzi et al. 1997; Decroocq et al. 2006; Nemchinov and Hadidi 1996). Here, we report genetic modifications involved in the adaptation of a cherry PPV-C isolate to $N$. benthamiana, the trade-offs of this adaptation in cherry infection, and the changes required to reestablish virulence on the natural host.

\section{A reliable PPV-C infectious cDNA clone with cherry specificity.}

It has been suggested that the adaptation of plant viruses to new hosts can have a fitness cost in the original host (AgudeloRomero et al. 2008). Thus, the mechanical propagation of the Rankovic and Pennsylvania PPV-D isolates in Nicotiana spp. and Pisum sativum, respectively, significantly reduced the ability of these viruses to reinfect peach (Dallot et al. 2001; Wallis et al. 2007). The inability of SwCMp (and its derived cDNA clone SwCM) to efficiently infect cherry (Table 2) suggests that genetic changes have been required to adapt the cherryderived natural isolate to Nicotiana spp, and these changes have brought with it a trade-off in the original host. In support of this assumption, isolates BY181 and BY101, which have only been propagated in cherry species, have a low fitness in Nicotiana spp. (Fig. 2).

One of these isolates, BY101, was used to build an additional PPV-C full-length cDNA clone, pICPPV-CaBY101n, which would be expected to conserve the natural host-specific pathogenicity features. CaBY101n more efficiently infected $P$. avium than other Prunus species (Fig. 3; Table 3). This result is in agreement with field observations that neither peaches nor plums have ever been found to be infected with the $C$ strain of PPV. The fact that viral accumulation levels in the inoculated leaves of $P$. domestica and $P$. persica were very low compared with those in $P$. avium (Fig. 3), suggests that the initial viral amplification is inefficient in the first two species, and thus, the systemic infection develops weakly in the cases in which it succeeds. Thus, it seems that cherry-specific factors are needed for PPV-C to reach high replication or cell-to-cell movement rates and establish efficient systemic infections.

\section{Genetic determinants involved in alternative adaptation to $N$. benthamiana and $P$. avium are located within the $\mathrm{C}-\mathrm{P3}(\mathrm{PIPO}) / 6 \mathrm{~K} 1 / \mathrm{N}-\mathrm{CI}$ coding sequences.}

The substitution of nucleotides 2,900 to 4,608 from SwCM with the corresponding sequence of BY101 (clone pICPPV- 
CBY101-2) (Fig. 1) provides SwCM with the genetic determinants for systemic movement in $P$. avium that were lost during its adaptation to Nicotiana spp. In BY101-2, the restoration of the ability to move systemically in $P$. avium brings with it a drastic drop in the efficiency of infection in $N$. benthamiana. The viral accumulation analyses suggest that the reestablishment of the viral systemic movement capacity in $P$. avium does not rely on the achievement of higher local amplification rates on the inoculated leaves since, here, SwCM was able to reach accumulation levels that were similar to those of BY101-2 (Fig. 4B). In contrast, the trade-off of the readaptation to cherry appears to affect either viral replication or local movement in $N$. benthamiana, as deduced from the low accumulation levels of BY101-2 as compared with those of SwCM in the inoculated leaves of this host (Fig. 4D). Therefore, overlapping host-specific determinants for several viral functions lay in the C-P3(PIPO)/6K1/N-CI region.

\section{Single amino acid changes are enough}

to facilitate the adaptation of the virus to a new host.

BY101-2 and SwCM were considered as the starting points for the process of adaptation to $N$. benthamiana and of readaptation to $P$. avium, respectively. Since these two viruses differ in eight amino acids, the generation of random recombinants by shuffling seemed to be the most convenient option in order to determine which amino acids were relevant for the alternative adaptation.

Clones containing the P1164 residue from SwCM in $6 \mathrm{~K} 1$ were preferentially selected in a competition experiment between shuffled clones in $N$. benthamiana (Fig. 5C). This result was further supported by an experiment of forced evolution by serial passages of the BY101-2 viral progeny in which not only this mutation was spontaneously introduced but also $\mathrm{S} 1169 \mathrm{~N}$ in CI, which is present in the published sequence of the $N$. benthamiana SoC-propagated isolate (Fanigliulo et al. 2003) and other point mutations (Table 4). The increased fitness of mutants $\mathrm{P}_{1164}, \mathrm{~N}_{1169}$, and $\mathrm{N}_{1171}$ indicates that there are alternative ways to allow a rapid adaptation to $N$. benthamiana just by introducing single mutations in $6 \mathrm{~K} 1$ or CI (Fig. 6B).

The competition of shuffled clones in $P$. avium resulted in the selection of the same single clone, C5, in two independent experiments (Fig. 5D), suggesting that the requirements for PPV to infect systemically are stricter in this host than in $N$. benthamiana. On the other hand, the strategy of forced evolution did not work in $P$. avium; the viral progeny of the very rare and limited systemic infections caused by SwCM had not incorporated any mutation that facilitated further viral propagation, and similarly, although the shuffled clone that was imposed in the competition experiment caused a very mild infection, it did not evolve to gain virulence. The different evolutionary potential of PPV in the two hosts might be a consequence of the virus having a more limited replication capacity in $P$. avium or of this host posing narrower bottlenecks to the viral spread.

The selection of clone $\mathrm{C} 5$ in the competition experiment indicates that mutations in either P3, CI, or both have a positive effect on systemic movement in cherry (Figs. 5 and 7). However, when C5 and other shuffled clones were inoculated individually, the viral accumulation levels of the viral progeny of clone C5 were lower than those achieved with the inoculation of clone $\mathrm{S}-33$, which only contained a single amino acid, T1164 in 6K1, derived from the cherry-adapted virus BY101 (Fig. 7). The reasons why the S-33 clone, in spite of its higher infection efficiency, was not selected in the competition experiments were not further investigated. Thus, a single amino acid change, P1164T in 6K1 (which is reciprocal to one that promotes the adaptation to $N$. benthamiana), is enough for the
Nicotiana-adapted virus SwCM to regain the systemic movement capacity in $P$. avium. However, additional changes in the $\mathrm{P} 3 / \mathrm{PIPO}$ region appear to enhance the efficiency of the virus in this host, as evidenced by comparing the infections caused by BY101-2, BY101-2-II, and S-33 (Fig. 7).

\section{Virus accumulation does not positively correlate with virulence in either $N$. benthamiana or $P$. avium.}

The point mutants of BY101-2 adapted to $N$. benthamiana $\left(\mathrm{P}_{1164}, \mathrm{~N}_{1169}, \mathrm{R}_{1054} \mathrm{~N}_{1171}\right.$, and $\left.\mathrm{N}_{1171}\right)$, which reached similar levels of systemic viral accumulation to SwCM (Fig. 6B), however, caused symptomatically milder infections that did not correspond with systemic necrosis.

Also, the P1164T mutation of clone S-33, which restored the systemic movement capacity of SwCM in P. avium, enabled virus accumulation levels that were similar to those obtained with clone BY101-2-II but only causing very mild symptoms (Fig. 7).

These results support the idea that a gain of fitness does not need to correlate with an increased virulence, which has been assessed not only for plant but also for animal viruses (Carrasco et al. 2007; Escriu et al. 2000; Herrera et al. 2007), and demonstrates the existence of symptom determinants overlapping but not coincident with those regulating virus replication and movement in the PPV C-P3(PIPO)/6K1/N-CI region, in agreement with previously reported results (Dallot et al. 2001; Sáenz et al. 2000).

\section{The putative role of the proteolytic cleavage between $6 \mathrm{~K} 1$ and $\mathrm{CI}$ in host adaptation of PPV-C.}

A single point mutation in amino acid 1,164 of $6 \mathrm{~K} 1$ enables the local and systemic spread of a cherry-adapted PPV-C isolate in $N$. benthamiana and restores the systemic movement capacity in P. avium of a Nicotiana-adapted PPV-C virus. Although the function of $6 \mathrm{~K} 1$ remains unknown, the fact that deleting or mutating this region impedes viral replication demonstrates that this potyviral protein, or protein fragment, plays a relevant role in potyviral infection (Kekarainen et al. 2002; Merits et al. 2002; Rodriguez-Cerezo et al. 1993). PPV 6K1 has been detected as a free peptide in vivo (Waltermann and Maiss 2006), but it has also been suggested that $6 \mathrm{~K} 1$ might play a role as part of the P3+6K1 product (Riechmann et al. 1995). Thus, a function of the mature $6 \mathrm{~K} 1$ protein or of partially processed products including $6 \mathrm{~K} 1$ could be responsible for the alternative adaptation of PPV-C isolates to cherry and Nicotiana spp.

It is remarkable that single mutations at the $\mathrm{N}$-terminus of CI (S1169N and D1171N, first and third positions of CI) facilitate virus adaptation to $N$. benthamiana in a similar way to the T1164P mutation at the C-terminus of 6K1. CI is an RNA helicase (Laín et al. 1990) that is involved in viral replication (Fernández et al. 1997) and movement (Carrington et al. 1998; López et al. 2001). It has a self-interaction domain at its N-terminal region (López et al. 2001) that is specifically involved in cell-to-cell movement. In fact, mutation DD3,4AA (affecting the third and fourth CI amino acids) abolishes Tobacco etch virus and PPV cell-to-cell movement but has no effect on replication (Carrington et al. 1998; Gómez de Cedrón et al. 2006). Thus, the D1171N mutation could adapt CI to specific host factors involved in virus cell-to cell spread, correcting the defect of cherry-adapted PPV-C isolates for local and systemic virus amplification in $N$. benthamiana.

The fact that mutations in two different proteins, $6 \mathrm{~K} 1$ and $\mathrm{CI}$, have the same phenotypic result, i.e., to facilitate systemic infection in $N$. benthamiana, could indicate that both proteins functionally interact in a common biological process, either as independent proteins or forming part of a single partially processed polyprotein precursor. This last assumption is challenged 
by the observation that $\mathrm{P} 3+6 \mathrm{~K} 1$ and $\mathrm{CI}+6 \mathrm{~K} 2$ rather than $6 \mathrm{~K} 1-\mathrm{CI}$ polyprotein processing intermediates were shown to accumulate in insect and plant cells (Merits et al. 2002).

In a more appealing hypothesis, the three single mutations that potentiate the systemic infection of PPV-C in N. benthamiana (T1164P, S1169N, and D1171N) could be affecting the cleavage site recognized by NIapro at the 6K1/CI junction. NIapro cleavage sites are characterized by conserved heptapeptides (Adams et al. 2005). T1164P and S1169N affect residues at positions P5 and $\mathrm{P}^{\prime}$, which have been shown to be nonessential for cleavage (Carrington and Dougherty 1988; Dougherty et al. 1988) but which can contribute to a fine regulation of the proteolytic processing (Dougherty et al. 1989). Moreover, mutation D1171N affects residue P3', which is outside the conserved motif but is also relevant for cleavage efficiency (García et al. 1992). Thus, our results could be suggesting that the proteolytic processing by NIapro between $6 \mathrm{~K} 1$ and CI needs to be modulated in a host-specific manner to render a fully active CI, necessary for cell-to-cell and subsequent systemic movement, and an active $\mathrm{P} 3-6 \mathrm{~K} 1$ product, necessary for viral replication. This complex hypothesis remains to be tested and opens new questions to be answered in the future.

\section{MATERIALS AND METHODS}

\section{Viruses.}

$N$. clevelandii tissue infected with the PPV-C SwCMp isolate was obtained from A. Crescenzi (Università degli Studi della Basilicata, Potenza, Italy). It was subjected to limited passages in $N$. clevelandii before being used for the construction of its derived infectious clone. The BY101 and BY181 PPV-C isolates were obtained from infected $P$. lannesiana (L2) and $P$. padus $\times P$. cerasus (Cepadus), respectively, in Minsk (Belarus) and were propagated in $P$. avium $\times P$. pseudocerasus 'Colt' (Malinowski et al. 2012).

\section{Plant hosts.}

P. avium 'Pontavium', $P$. domestica 'Brompton', and $P$. persica 'GF305' seeds were obtained from Pépinières Lafond (Valreas, France). Prior to germinating, the endocarp from all seeds was mechanically removed and seeds were soaked overnight in water (including $150 \mu \mathrm{M}$ gibberellic acid for $P$. avium seeds) with gentle agitation. Afterwards, seed coats were mechanically removed and seeds were germinated in moist vermiculite under greenhouse conditions (16 h of light with supplementary illumination when needed and a temperature range of 19 to $23^{\circ} \mathrm{C}$ ). Approximately 4 weeks after germination, seedlings were transferred to soil and were maintained in the same conditions.

$N$. benthamiana, $N$. clevelandii, $N$. tabacum, and $C$. foetidum were maintained under the same greenhouse conditions $(16 \mathrm{~h}$ of light with supplementary illumination when needed and a temperature range of 19 to $\left.23^{\circ} \mathrm{C}\right)$. A. thaliana seeds were germinated and were maintained in a growth chamber (8-h-light photoperiod and a temperature of $22^{\circ} \mathrm{C}$ ).

\section{IC-RT-PCR.}

RT-PCR assays preceded by immunocapture (IC-RT-PCR) for infected $N$. benthamiana samples were performed as previously described (Maliogka et al. 2012).

For IC-RT-PCR assays of $P$. avium infected tissue, samples were homogenized in PBS-TPB buffer (PBS 1X, 0.05\% Tween 20, 2\% PVP-40, $0.5 \% \mathrm{BSA}, \mathrm{pH} 7.4$ ) (16 ml per $\mathrm{g}$ of tissue) and centrifuged at $18,000 \times g$ at $4^{\circ} \mathrm{C}$ for $3 \mathrm{~min}$. The supernatant was incubated overnight at $4^{\circ} \mathrm{C}$ in tubes previously coated with anti-PPV IgG (prepared according to Steinbuch and Audran 1969). The incubation was followed by four washing steps with PBS-Tween buffer (16 mM PBS, 0.1 M NaCl, $0.5 \mathrm{~g}$ Tween 20, pH 7.2). Finally, a short wash with $0.01 \mathrm{M}$ Tris-HCl pH 8 was performed. In all cases, RT-PCRs were performed using a Titan Kit (Roche Molecular Biochemicals, Branchburg, NJ, U.S.A.) with specific primers targeting the sequences to be amplified. For sequence analysis, RT-PCR products were purified using the FavorPrep Gel/PCR purification mini kit (Favorgen Biotech. Corp., Taiwan, Japan) and sequenced by Macrogen Europe (Amsterdam, The Netherlands).

\section{Construction of full-length cDNA infectious clones.}

For all constructs, amplification of viral sequences from infected tissue by IC-RT-PCR was performed as described above. PCR reactions were performed with Pwo DNA polymerase (Roche Applied Science, Indianapolis, IN, U.S.A.). DNA digests were carried out using either NEB (New England Biolabs, Ipswich, MA, U.S.A.) or Thermo Scientific (Thermo Fisher Scientific, Inc., Waltham, MA, U.S.A.) restriction enzymes. All ligations were performed using T4 DNA ligase (Thermo Fisher Scientific, Inc., Waltham, MA, U.S.A.). Ligation mixtures were transformed either by electroporation of $E$. coli $\mathrm{DH} 10 \mathrm{~b}$ or heat-shock method of $E$. coli $\mathrm{DH} 5 \alpha$ bacteria.

Details of the construction of pICPPV-SwCM, pICPPVCaBY101n and their derivatives are supplied in the Supplementary Text S1.

For the construction of the recombinant shuffled library, first, two overlapping PCR fragments from each of the clones pICPPV-SwCM and pICPPV-CBY101-2 were amplified using primers \#1990 and \#1991 (first fragment: $1139 \mathrm{bp}$ ) and \#505 and \#1706 (second fragment: $1852 \mathrm{bp}$ ), and were purified with FavorPrep Gel/PCR purification mini kit (Favorgen Biotech. Corp., Taiwan, Japan).

Two micrograms of mixed DNA (from pICPPV-SwCM and pICPPV-CBY101-2) of each fragment were digested with DNAse I $\left(5 \times 10^{-4} \mathrm{U} / \mu \mathrm{l}\right)$ for $6 \mathrm{~min}$. The reaction was stopped by adding $10 \mathrm{mM}$ EDTA and heating at $90^{\circ} \mathrm{C}$ for $10 \mathrm{~min}$. Smears sized under $450 \mathrm{bp}$, were gel-purified by the freezeand-squeeze method. Digested DNA fragments from the smears of the first and second fragments were mixed and shuffled by means of a PCR without primers. The shuffled PCR product was used as a template for a final PCR using primers \#1992 and \#1993 in which a full-sized band (2217 bp) was amplified and gel-purified by freeze-and-squeeze. To avoid mutations, all PCRs were performed using Phusion High-Fidelity DNA polymerase (New England Biolabs, Ipswich, MA, U.S.A.).

The shuffled band was cloned into pICPPV-SwCM using SexAI (2899) and SalI (4797) restriction sites. Individual shuffled clones were obtained by electroporation of E. coli DH10b bacteria.

The shuffled region of 45 individual clones was totally or partially sequenced. To obtain the cDNA library, 139 positive clones were individually transformed into $E$. coli $\mathrm{DH} 5 \alpha$ bacteria. One colony of each clone was selected and all of them were cultured together. A single maxiprep of the shuffled plasmid library was prepared from the mixed culture.

\section{Biolistic inoculation.}

The Helios Gene Gun system (Bio-Rad, Hercules, CA, U.S.A.) was used for biolistic inoculation. Microcarrier cartridges were prepared from two different clones per construct, with $1.0 \mu \mathrm{m}$ gold particles coated with the different plasmids at a DNA loading ratio of $2 \mu \mathrm{g}$ gold $\mathrm{mg}^{-1}$ and a microcarrier loading of $0.5 \mathrm{mg}$ per shot. Helium pressure of 7 bar was used for shooting either Nicotiana species or P. avium. Ten bar was used for $P$. persica and $P$. domestica. Each cartridge was shot twice onto two leaves of each plant. Two leaves were inoculated in Nicotiana species (aged approximately 3 weeks) and 
three to four leaves were inoculated in Prunus species (aged approximately 8 weeks).

\section{Mechanical hand inoculation.}

For manual inoculation, infected plant leaves that had previously been ground to a fine powder under liquid nitrogen, were homogenized with $5 \mathrm{mM}$ sodium phosphate buffer, $\mathrm{pH} 7.4(2 \mathrm{ml}$ per $g$ of tissue) using vortex. Fifteen to twenty microliters of the extracts were used to inoculate each plant on two leaves.

For the inoculation of some virus mutants, plasmid minipreps were prepared at a concentration of approximately $250 \mathrm{ng} / \mu \mathrm{l}$ and DNA was directly rubbed on three leaves.

All plants were dusted with Carborundum prior to inoculation.

\section{Immunoblot analysis.}

Samples from inoculated or upper leaves (and equivalent samples from plants used as negative controls) were collected and ground to a fine powder under liquid nitrogen and stored at $-80^{\circ} \mathrm{C}$ until use. Protein extracts were prepared by thawing the powder in extraction buffer $(150 \mathrm{mM}$ Tris- $\mathrm{HCl}, \mathrm{pH} 7.5,6$ $\mathrm{M}$ urea, $2 \%$ sodium dodecyl sulphate and 5\% $\beta$-mercaptoethanol) ( $2 \mathrm{ml}$ per $\mathrm{g}$ of tissue in the case of $N$. benthamiana samples and $4 \mathrm{ml}$ per $\mathrm{g}$ in the case of Prunus samples). Samples were boiled for $10 \mathrm{~min}$, and cell debris was removed by centrifugation at $18,000 \times g$ at $4^{\circ} \mathrm{C}$ for $10 \mathrm{~min}$ in the case of $N$. benthamiana samples and $15 \mathrm{~min}$ in the case of Prunus samples. Supernatants were resolved on sodium dodecyl sulphatepolyacrylamide gels (12\% acrylamide) and electroblotted to a nitrocellulose membrane. Ponceau red staining was used to check the global protein content of samples. Anti PPV CP rabbit serum was used as primary antibody and horseradish peroxidase-conjugated goat anti-rabbit immunoglobulin G (Jackson ImmunoResearch, West Grove, PA, U.S.A) as secondary reagent. The immunostained proteins were visualized by enhanced chemiluminiscence detection with a LifeABlot kit (Euroclone S.p.A., Siziano, Italy).

\section{ACKNOWLEDGMENTS}

We thank B. García for technical assistance and A. Valli and C. Simon for helpful commentaries on the manuscript. We are also grateful to A. Crescenzi for providing us with the PPV-C SwCMp isolate. This work was supported by grants from Spanish MICINN (BIO2010-18541) and the European Union (KBBE-204429). M. Calvo was the recipient of an I3P fellowship from CSIC-Fondo Social Europeo. M. Calvo performed all the experiments shown in this article, participated in the experimental design and in writing the manuscript. T. Malinowski optimized the propagation of BY101 and BY181 isolates in cherry plants under laboratory conditions. J. A. García coordinated the work and participated in the experimental design and in writing the manuscript. All authors read and approved the final manuscript.

\section{LITERATURE CITED}

Adams, M. J., Antoniw, J. F., and Beaudoin, F. 2005. Overview and analysis of the polyprotein cleavage sites in the family Potyviridae. Mol. Plant Pathol. 6:471-487.

Agudelo-Romero, P., de la Iglesia, F., and Elena, S. 2008. The pleiotropic cost of host-specialization in Tobacco etch potyvirus. Infect. Genet. Evol. 8:806-814.

Atanasoff. 1932. Plum pox. A new virus disease. Yearbook University of Sofia, Faculty of Agriculture 11:49-69.

Cambra, M., Capote, N., Myrta, A., and Llácer, G. 2006a. Plum pox virus and the estimated costs associated with sharka disease. EPPO Bull. 36:202-204.

Cambra, M., Boscia, D., Myrta, A., Palkovics, L., Navrátil, M., Barba, M., Gorris, M. T., and Capote, N. 2006b. Serological detection and characterisation of Plum pox virus. EPPO Bull. 36:254-261.

Candresse, T., and Cambra, M. 2006. Causal agent of sharka disease: Historical perspective and current status of Plum pox virus strains. EPPO
Bull. 36:239-246.

Carrasco, P., de la Iglesia, F., and Elena, S. 2007. Distribution of fitness and virulence effects caused by single-nucleotide substitutions in Tobacco etch virus. J. Virol. 81:12979-12984.

Carrington, J. C., and Dougherty, W. G. 1988. A viral cleavage site cassette: Identification of amino acid sequences required for tobacco etch virus polyprotein processing. Proc. Natl. Acad. Sci. U.S.A. 85:33913395.

Carrington, J. C., Jensen, P. E., and Schaad, M. C. 1998. Genetic evidence for an essential role for potyvirus CI protein in cell-to-cell movement. Plant J. 14:393-400.

Chirkov, S., Ivanov, P., and Sheveleva, A. 2013. Detection and partial molecular characterization of atypical plum pox virus isolates from naturally infected sour cherry. Arch. Virol. 158:1383-1387.

Chung, B. Y. W., Miller, W. A., Atkins, J. F., and Firth, A. E. 2008. An overlapping essential gene in the Potyviridae. Proc. Natl. Acad. Sci. U.S.A. 105:5897-5902.

Crescenzi, A., dAquino, L., Comes, S., Nuzzaci, M., Piazzolla, P., Boscia, D., and Hadidi, A. 1997. Characterization of the sweet cherry isolate of Plum pox potyvirus. Plant Dis. 81:711-714.

Dallot, S., Quiot-Douine, L., Sáenz, P., Cervera, M. T., García, J. A., and Quiot, J. B. 2001. Identification of Plum pox virus determinants implicated in specific interactions with different Prunus spp. Phytopathology 91:159-164.

Decroocq, V., Sicard, O., Alamillo, J. M., Lansac, M., Eyquard, J. P., García, J. A., Candresse, T., Le Gall, O., and Revers, F. 2006. Multiple resistance traits control Plum pox virus infection in Arabidopsis thaliana. Mol. Plant-Microbe Interact. 19:541-549.

Dosba, F., Maison, P., Lansac, M., and Massonie, G. 1987. Experimental transmission of Plum pox virus (PPV) to Prunus mahaleb and Prunus avium. J. Phytopathol 120:199-204.

Dougherty, W. G., Carrington, J. C., Cary, S. M., and Parks, T. D. 1988 Biochemical and mutational analysis of a plant virus polyprotein cleavage site. EMBO (Eur. Mol. Biol. Organ.) J. 7:1281-1287.

Dougherty, W. G., Cary, S. M., and Parks, T. D. 1989. Molecular genetic analysis of a plant virus polyprotein cleavage site: A model. Virology 171:356-364.

Escriu, F., Fraile, A., and Garcia-Arenal, F. 2000. Evolution of virulence in natural populations of the satellite RNA of Cucumber mosaic virus. Phytopathology 90:480-485.

Fanigliulo, A., Comes, S., Maiss, E., Piazzolla, P., and Crescenzi, A. 2003. The complete nucleotide sequence of Plum pox virus isolates from sweet (PPV-SwC) and sour (PPV-SoC) cherry and their taxonomic relationships within the species. Arch. Virol. 148:2137-2153.

Fernández, A., Guo, H. S., Sáenz, P., Simón-Buela, L., Gómez de Cedrón, M., and García, J. A. 1997. The motif V of Plum pox potyvirus CI RNA helicase is involved in NTP hydrolysis and is essential for virus RNA replication. Nucleic Acids Res. 25:4474-4480.

García, J. A., Martín, M. T., Cervera, M. T., and Riechmann, J. L. 1992. Proteolytic processing of the Plum pox potyvirus polyprotein by the NIa protease at a novel cleavage site. Virology 188:697-703.

García, J. A., Glasa, M, Cambra, M. and Candresse, T. 2013. Plum pox virus and sharka: A model potyvirus and a major disease. Mol. Plant Pathol. Published online. doi: 10.1111/mpp

Glasa, M., Prikhodko, Y., Predajňa, L., Nagyová, A., Shneyder, Y., Zhivaeva, T., Šubr, Z., Cambra, M., and Candresse, T. 2013. Characterization of sour cherry isolates of Plum pox virus from the Volga basin in Russia reveals a new cherry strain of the virus. Phytopathology 103:972-979.

Gómez de Cedrón, M., Osaba, L., López, L., and García, J. A. 2006. Genetic analysis of the function of the plum pox virus CI RNA helicase in virus movement. Virus Res. 116:136-145.

Goodin, M., Zaitlin, D., Naidu, R. A., and Lommel, S. A. 2008. Nicotiana benthamiana: Its history and future as a model for plant-pathogen interactions. Mol. Plant-Microbe Interact. 21:1015-1026.

Herrera, M., García-Arriaza, J., Pariente, N., Escarmís, C., and Domingo, E. 2007. Molecular basis for a lack of correlation between viral fitness and cell killing capacity. PLoS Pathog. 3:e53. Online publication.

Hull, R. 2002. Matthews' Plant Virology. Academic Press, London.

James, D., and Varga, A. 2005. Nucleotide sequence analysis of Plum pox virus isolate W3174: Evidence of a new strain. Virus Res. 110:143-150.

Kajic, V., Černi, S., and Škoric, D. 2012. Plum pox virus in sour cherry in Croatia. Page 157 in: Book of Abstracts, 22nd International Conference on Virus and Other Graft Transmissible Diseases of Fruit Crops, Rome.

Kekarainen, T., Savilahti, H., and Valkonen, J. 2002. Functional genomics on potato virus A: Virus genome-wide map of sites essential for virus propagation. Genome Res. 12:584-594.

Laín, S., Riechmann, J. L., and García, J. A. 1990. RNA helicase: A novel activity associated with a protein encoded by a positive strand RNA virus. Nucleic Acids Res. 18:7003-7006. 
López, L., Urzainqui, A., Domínguez, E., and García, J. A. 2001. Identification of an N-terminal domain of the Plum pox potyvirus CI RNA helicase involved in self-interaction in a yeast two-hybrid system. J. Gen. Virol. 82:677-686.

López-Moya, J. J., and García, J. A. 2000. Construction of a stable and highly infectious intron-containing cDNA clone of Plum pox potyvirus and its use to infect plants by particle bombardment. Virus Res. 68:99107.

López-Moya, J. J., Fernández-Fernández, M. R., Cambra, M., and García, J. A. 2000. Biotechnological aspects of plum pox virus. J. Biotechnol. 76:121-136.

Maiss, E., Timpe, U., Briske-Rode, A., Leseman, D.-E., and Casper, R. 1992. Infectious in vivo transcripts of a Plum pox potyvirus full-length cDNA clone containing the cauliflower mosaic virus 35S RNA promoter. J. Gen. Virol. 73:709-713.

Malinowski, T., Sowik, I., Salavei, A. V., and Kukharchyk, N. V. 2012. Partial characterisation of biological properties of PPV-C isolates found in Belarus and establishment of in vitro cultures of infected L2 and OWP-6 rootstocks. Page 152 in: Book of Abstracts, 22nd International Conference on Virus and Other Graft Transmissible Diseases of Fruit Crops, Rome.

Maliogka, V. I ., Salvador, B., Carbonell, A., Saénz, P., San León, D., Oliveros, J. C., Delgadillo, M. O., García, J. A., and Simón-Mateo, C. 2012. Virus variants with differences in the P1 protein coexist in a Plum pox virus population and display particular host-dependent pathogenicity features. Mol. Plant Pathol. 13:877-886.

Merits, A., Rajamäki, M., Lindholm, P., Runeberg-Roos, P., Kekarainen, T., Puustinen, P., Mäkeläinen, K., Valkonen, J., and Saarma, M. 2002. Proteolytic processing of potyviral proteins and polyprotein processing intermediates in insect and plant cells. J. Gen. Virol. 83:1211-1221.

Nemchinov, L., and Hadidi, A. 1996. Characterization of the sour cherry strain of plum pox virus. Phytopathology 86:575-580.

Nemchinov, L., Hadidi, A., Maiss, E., Cambra, M., Candresse, T., and Damsteegt, V. 1996. Sour cherry strain of Plum pox potyvirus (PPV): Molecular and serological evidence for a new subgroup of PPV strains. Phytopathology 86:1215-1221.

Nemchinov, L., Hadidi, A., Kölber, M., and Németh, M. 1998. Molecular evidence for the occurrence of Plum pox virus-cherry subgroup in Hungary. Acta Hortic. 472:503-510.

Olmos, A., Bertolini, E., and Cambra, M. 2007. Isothermal amplification coupled with rapid flow-through hybridisation for sensitive diagnosis of Plum pox virus. J. Virol. Methods 139:111-115.

Pasquini, G., Barba, M., Hadidi, A., Faggioli, F., Negri, R., Sobol, I., Tiberini, A., Caglayan, K., Mazyad, H., Anfoka, G., Ghanim, M., Zeidan, M., and Czosnek, H. 2008. Oligonucleotide microarray-based detection and genotyping of Plum pox virus. J. Virol. Methods 147:118-126.

Predajňa, L., Nagyova, A., Glasa, M., and Šubr, Z. 2012. Cloning of the complete infectious cDNA of the plum pox virus strain PPV-Rec. Acta Virol. 56:129-132.
Riechmann, J. L., Laín, S., and García, J. A. 1990. Infectious in vitro transcripts from a Plum pox potyvirus cDNA clone. Virology 177:710-716.

Riechmann, J. L., Cervera, M. T., and García, J. A. 1995. Processing of the plum pox virus polyprotein at the $\mathrm{P} 3-6 \mathrm{~K}_{1}$ junction is not required for virus viability. J. Gen. Virol. 76:951-956.

Rodriguez-Cerezo, E., Ammar, E. D., Pirone, T. P., and Shaw, J. G. 1993. Association of the non-structural P3 viral protein with cylindrical inclusions in potyvirus-infected cells. J. Gen. Virol. 74 (Pt 9):1945-1949.

Sáenz, P., Cervera, M. T., Dallot, S., Quiot, L., Quiot, J. B., Riechmann, J. L., and García, J. A. 2000. Identification of a pathogenicity determinan of Plum pox virus in the sequence encoding the C-terminal region of protein P3+6K 1 . J. Gen. Virol. 81:557-566.

Salvador, B., García, J. A., and Simón-Mateo, C. 2006. Causal agent of sharka disease: Plum pox virus genome and function of gene products. EPPO Bull. 36:229-238.

Salvador, B., Delgadillo, M. O., Saénz, P., García, J. A., and Simón-Mateo, C. 2008. Identification of Plum pox virus pathogenicity determinants in herbaceous and woody hosts. Mol. Plant-Microbe Interact. 21:20-29.

Serçe, C., Candresse, T., Svanella-Dumas, L., Krizbai, L., Gazel, M., and Caglayan, K. 2009. Further characterization of a new recombinant group of Plum pox virus isolates, PPV-T, found in orchards in the Ankara province of Turkey. Virus Res. 142:121-126.

Sochor, J., Babula, P., Adam, V., Krska, B., and Kizek, R. 2012. Sharka: The past, the present and the future. Viruses 4:2853-2901.

Steinbuch, M. and Audran, R. 1969. The isolation of IgG from mammalian sera with the aid of caprylic acid. Arch. Biochem. Biophys. 134:279284.

Šubr, Z., and Glasa, M. 2013. Unfolding the secrets of Plum pox virus: From epidemiology to genomics. Acta Virol. 57:217-228.

Tobias, I., Palkovics, L., Tzekova, L., and Balazs, E. 2001. Replacement of the coat protein gene of Plum pox potyvirus with that of zucchini yellow mosaic potyvirus: Characterization of the hybrid potyvirus. Virus Res. 76:9-16.

van Oosten, H. J. 1970. Herbaceous host plants for the sharka (plum pox) virus. Neth. J. Plant Pathol. 76:253-260.

Varga, A., and James, D. 2006. Use of reverse transcription loop-mediated isothermal amplification for the detection of Plum pox virus. J. Virol. Methods 138:184-190.

Wallis, C. M., Stone, A. L., Sherman, D. J., Damsteegt, V. D., Gildow, F. E., and Schneider, W. L. 2007. Adaptation of plum pox virus to a herbaceous host (Pisum sativum) following serial passages. J. Gen. Virol. 88:2839-2845.

Waltermann, A., and Maiss, E. 2006. Detection of 6K1 as a mature protein of $6 \mathrm{kDa}$ in plum pox virus-infected Nicotiana benthamiana. J. Gen. Virol. 87:2381-2386.

Wetzel, T., Candresse, T., Ravelonandro, M., Delbos, R. P., Mazyad, H., Aboul-Ata, A. E., and Dunez, J. 1991. Nucleotide sequence of the 3' terminal region of the RNA of the El Amar strain of Plum pox potyvirus. J. Gen. Virol. 72:1741-1746. 